\title{
Customer Discrimination and Employment Outcomes: Theory and Evidence from the French Labor Market*
}

\author{
Pierre-Philippe Combes ${ }^{\dagger} \quad$ Bruno Decreuse ${ }^{\ddagger}$ \\ Morgane Laouénan ${ }^{\S} \quad$ Alain Trannoy
}

January 2013

\begin{abstract}
The paper investigates the link between the over-exposure of African immigrants to unemployment in France and their under-representation in jobs in contact with customers. We build a two-sector matching model with ethnic sector-specific preferences, economy-wide employer discrimination, and customer discrimination in jobs in contact with customers. The outcomes of the model allow us to build a test of ethnic discrimination in general and customer discrimination in particular. We run the test on French individual data in a cross-section of local labor markets (Employment Areas). Our results show that there is both employer and customer discrimination in the French labor market.
\end{abstract}

JEL classification: J15, J61, R23

Keywords: Customer Discrimination, Matching Frictions, Jobs in contact, Ethnic Unemployment.

*This paper has benefited from discussions with Moshe Buchinsky, Laurent Gobillon, Jon Guryan, Ruben Hernandez, Kevin Lang, Robert Margo, Benoit Schmutz, Etienne Wasmer and Yves Zenou. We also wish to thank seminar participants at Boston University, University of Aix-Marseilles, Sciences-Po and Centre d'Etudes de l'Emploi, as well as participants to the SOLE Conference in Chicago, to the EALE Conference in Cyprus, to the Louis-André Gérard Varet conference in Marseilles, to the EEA conference in Glasgow and to the Journées d'Economie Spatiale in Dijon. Data was made available by the Centre Maurice Halbwachs. This research was partly funded by the Direction de l'Animation de la Recherche, des Etudes et des Statistiques (Dares). The usual caveat applies.

${ }^{\dagger}$ Aix-Marseille Université, CEPR, ppcombes@univmed.fr

${ }^{\ddagger}$ Aix-Marseille Université, decreuse@univmed.fr

${ }^{\S}$ Université catholique de Louvain, morgane.laouenan@uclouvain.be

`Aix-Marseille Université, EHESS, alain.trannoy@univmed.fr 


\section{Introduction}

The serious consequences of a widespread prejudice against a minority group come readily to mind. In the long run, a divided society can emerge with a part of the population feeling itself to be excluded from the benefits of prosperity and inclusion. In France, African immigrants (first generation) and those whose parents were born in an African country (second generation) number about 5 million. They mainly originate from former French colonies and come from poor social backgrounds; prejudice against them is deeply rooted in the colonial past. It is not far-fetched to surmise that this prejudice can persist in generations that did not experience colonization. The broad goal of the paper is to explore the causal implication of this prejudice on the labor-market outcome differentials between Afro-French and French natives ${ }^{1}$.

African immigrants are both under-represented in jobs involving contact with customers (hereafter, contact jobs) and over-exposed to unemployment. The ethnic differential rate of occupation in contact jobs is about 10 percentage points; the unemployment rate differential between Africans and French natives also amounts to about 11 percentage points. Most of such differentials cannot be explained by the uneven distribution of skills between these two ethnic groups (Aeberhardt et al. (2010)). It is tempting to connect the two ethnic differentials in one way or another. This leads to the following conjecture: people with African origins are discriminated against in contact jobs, thereby reducing dramatically the set of employment opportunities offered to them. The comparison with immigrants of other origin militates in favor of such an explanation. Unlike African immigrants, European immigrants have the same probability of being employed and of being in contact with customers as French natives. They are much less inclined to suffer from ethnic prejudice since they come from countries which have not been dominated by the French. Obviously, this crude comparison is not enough to convince the reader of the robustness of the link between the two deficits the African immigrants suffer from. The aim of the paper is to investigate this conjecture in depth.

Let us emphasize that under-representation in a specific occupation does not mean that a group is discriminated against. Suppose for instance that Africans and French natives are seemingly identical except for color and that there are two types of jobs, with and without contact with consumers. If African immigrants do not like contact jobs as much as French natives, then they will be naturally under-represented in such jobs. In a perfect labor market, such sectorial tastes for jobs have no effects on overall unemployment risks. However, in a context of job scarcity turning down a number of potential offers may translate into lower chances of having a job. This can explain and relate the two facts reported above without even appealing to discrimination. The lesson of this thought experiment is that ethnic-specific sectorial preferences need to be accounted for before properly assessing discrimination.

If this conjecture were established, it would call for some public policy intervention because without it the phenomenon can sustain. As highlighted by Becker (1957), the type of discrimination matters in the long run. In the case of employer discrimination, employers hold a 'taste' for dis-

\footnotetext{
${ }^{1}$ We consider Afro-French as immigrants from Sub-Saharan Africa and North Africa.
} 
crimination, meaning that they see a disutility in employing minority workers. However, employer discrimination is costly for the firm and its shareholders and so it tends to recede over time, at least if the competition is sufficiently fierce. In case of customer discrimination, employers internalize the customers' prejudice against workers coming from a minority. Customer discrimination is rooted in profit maximization and, therefore, tends to persist. Moreover, the decline of industry and the growth of the consumer service sector mean that job opportunities are increasingly exposed to public contact. The share of contact jobs has been on the rise over the past forty years in France: The share of unskilled contact jobs went from $31.6 \%$ in 1968 to $52.7 \%$ in 1999 . Improving employment opportunities for African immigrants will prove difficult if they are excluded from half the jobs.

The above observations show that two other phenomena can compete in explaining the underrepresentation of African immigrants in contact jobs, that is employer discrimination and ethnic specific preferences in some occupations. This paper is an attempt to single out customer discrimination from these two competing explanations. We develop a theoretical model that provides a way to test for the presence of customer discrimination in a frictional labor market. We then run the test on French data and find evidence of customer discrimination with sizable implications for African unemployment and occupations.

There is a growing literature on ethnic discrimination in the French labor market despite the fact that the French Constitution prohibits the collection of data on ethnic groups and so public datasets provide imperfect information on minorities. A first piece of evidence comes from audit studies that show that African workers have a lower chance of being interviewed, all else being equal (see, e.g., Cediey and Foroni (2006); Duguet et al. (2010)). Very few studies use survey data and document the over-exposure of African workers to unemployment risk (see, e.g., Aeberhardt et al. (2010) ; Algan et al. (2010)). The main message of these papers is that residual unemployment disparity is very high, whereas residual wage disparity is much more tenuous. Africans and French natives seem to receive equal pay when they have similar characteristics. Our analysis focuses on unemployment disparity rather than on wage disparity because it is reasonable to postulate that, if any, discrimination in the French labor market translates into employment rationing instead of wage reductions.

Section 2 presents a two-sector model (with and without contact with consumers), with two ethnic groups (Africans and French natives), sector-specific abilities that differ across ethnic groups, employer discrimination, and customer discrimination in contact jobs. The model is based on four key identifying assumptions. The first is that there is discrimination of some kind if and only if the the pool of prejudiced jobs in the whole population strictly increases with the proportion of French natives. This phenomenon may simply result from a size effect: at given prejudiced proportion in the French-native population, the number of discriminating individuals increases with the share of French natives. However, the phenomenon may also arise when prejudice among French natives decreases with exposure to African immigrants. One way to rationalize this assumption is to consider that African employers are more likely to hire African employees than French-native employers. Provided 
that the proportion of African employers decreases with the Non-African proportion, the likelihood of suffering from employer discrimination also decreases with such a proportion. ${ }^{2}$. The same mechanism is also applied to African consumers : African consumers are more likely to prefer interacting with African employees than with their French-native counterparts. Some empirical studies have proved these two mechanisms in the US. They show that the racial composition of individuals at the local level affects the hiring of ethnic employees. Giuliano et al. (2009) find that manager race is a significant determinant of the racial composition of new hires. They show that the probability a new hire is black is between 3.5 and 4.0 percentage points lower under non-black managers than it is under black managers. They justify this result in arguing that managers prefer to supervise racially similar employees, or be biased against racially dissimilar employees. In the same manner, Holzer and Ihlanfeldt (1998) show that the racial composition of an establishment's customers has sizable effects on the race of who gets hired, especially in jobs in contact with consumers. Especially, they show that the presence of black or Hispanic customers at an establishment has significant positive effects on the hiring of employees from these two groups.

The second assumption is that the sensitivity of employer discrimination vis-à-vis the proportion of prejudiced people does not vary across sectors. We actually need a weaker property: employer discrimination in contact jobs must not be more responsive to changes in the proportion of prejudiced people than in the rest of the economy. ${ }^{3}$ The third assumption is that customer discrimination only arises in the context of contact jobs. Prejudiced consumers do not care about workers with whom they do not interact. The final assumption is that employer type as well as consumer type cannot be perfectly observed. We consider two popular ways to model job search. We start with the case where search is undirected; matching is random as a result. We then examine the case where search is directed towards a particular sector. There, workers self-select across sectors according to comparative advantage.

The model predicts ethnic-specific unemployment rates and ethnic-specific distribution of occupations as functions of three local labor market characteristics: a) the probability of locating a vacancy; b) the proportion of jobs involving contact with consumers; c) the proportion of Frenchnative residents. The model provides a way to test the existence of ethnic discrimination and whether it is at least partly due to consumer tastes. We rely on the two following theoretical outcomes of the model. First, if the ethnic differential unemployment probability is positively affected by the proportion of Non-African residents, then there is ethnic (either customer or employer) discrimination. Second, there is customer discrimination if and only if there is ethnic discrimination and the

\footnotetext{
${ }^{2}$ The 1990 French Census gives credit to this argument. Let us name 'employers' people whose occupation number is 21 (craftsmen), 22 (corporate managers), 23 (shopkeepers). At employment area level, a one-standard-deviation increase in the Non-African proportion increases the proportion of African employers by 0.82 of its standard deviation. The results are marginally affected when we remove craftsmen from the employer group.

${ }^{3}$ In the US, an employer is required to file an Employer Information Report to the U.S. Equal Employment Opportunity Commission if it employs 100 or more employees. Therefore, large firms should be more inclined to improve the fraction of minority hires. If we suppose that jobs in contact with consumers are mostly in smaller firms, it suggests that employer discrimination could be stronger in this sector. However, such Anti-Discrimination Laws have not been implemented yet in France.
} 
ethnic differential probability of working in a contact job is negatively impacted by the proportion of Non-Africans.

On the theoretical side, our paper completes the literature on discrimination in frictional environments. The key insight from this literature is the following: when the labor market is frictional, labor market mobility is reduced and discrimination in a sufficiently large group of firms increases the odds of unemployment. Most of the papers focus on employer discrimination and its implications for wage differentials (see Black (1995), Bowlus and Eckstein (1998), Rosen (2003) and Lang et al. $(2005)) .^{4}$

Section 3 tests our model on French data at the Employment Area level ${ }^{5}$. Our paper uses the 1990 French census and examines how the individual probability of being unemployed and the individual probability of working in a contact job respond to the local discriminatory forces. Importantly, we consider both the local share of contact jobs and the local proportion of Non-African population as the two discriminatory forces, enabling the discriminating channel to be identified. The latter variable comes directly from our first identifying assumption. We develop a two-step procedure. In the first step, we regress individual labor market outcomes on a set of individual characteristics, on EA fixed-effects, and on EA fixed-effects interacted with a dummy indicating whether the individual is African or not. The contact job probability estimation accounts for sample selection bias along the lines of Heckman's model (Heckman (1979)). We then focus on the estimated EA fixed-effects interacted with the African dummy. Such parameters provide estimates of the ethnic unemployment rate differential and the ethnic differential in the probability of occupying a contact job, both adjusted for observable individual characteristics and EA fixed effects. In the second step, we regress this set of fixed-effects on the discriminatory forces at EA level: the local share of Non-Africans and the local share of contact jobs. We consider a linear combination of them augmented with their interaction.

We obtain two main results. We find that the residual ethnic unemployment rate differential is larger in EAs where both the proportions of contact jobs and of Non-Africans are high. The bulk of the effect comes from the interaction of these two proportions. In other words, the presence of a large number of contact jobs in an EA where there are many Non-Africans is detrimental to the job opportunities of African workers. Under our identifying assumptions this result indicates the presence of ethnic discrimination. We also find that the residual ethnic differential in the probability of occupying a contact job is larger in EAs where the proportion of Non-African residents is large. According to the second result of our model, this proves the presence of customer discrimination in the French labor market.

We check the robustness of our result through different means. First, we assess the quantitative impacts of our estimates. We then discuss the endogeneity of African location, which is likely to bias upwards our test of discrimination, and perform IV estimates, confirming our findings. We also question our measure of the individual contact probability and show that it does not affect the

\footnotetext{
${ }^{4}$ In Rosen (2003), workers and firms bargain over the wage, while Black (1995), Bowlus and Eckstein (1998) and Lang et al. (2005) assume that firms post non-negotiable wages along with jobs.

${ }^{5} \mathrm{EA}=$ zone d'emploi in French.
} 
relevance of our test of customer discrimination. We finally explain why some alternative EA-specific covariates are not included in our econometric specification.

In contrast to employer discrimination, econometric studies on customer discrimination are sparse, mainly because consumers' behavior and prejudices are difficult to quantify. A large literature on consumer discrimination can be found in papers using data from professional sports leagues. The main advantage of professional sports data is that they include extensive measures of the performance and compensation of athletes as unbiased proxies of productivity ${ }^{6}$. Nardinelli and Simon (1990) analyze customer effects by focusing on the prices of baseball cards for white and black players while Kahn and Sherer (1988) study the racial compensation differences of professional basketball players. Both studies show their results are consistent with the idea of customer discrimination. A few analyses of customer discrimination in labor markets use the racial composition of residents in geographical areas as a proxy for consumer composition of firms located in those areas. Holzer and Ihlanfeldt (1998) analyzed the effect of consumer racial composition on the race of newly hired employees, whereas Giuliano et al. (2009) and Giuliano et al. (2010) studied the impact of this racial composition on firms' sales. There have also been a number of experimental contributions to the customer discrimination literature: Ihlanfeldt and Young (1994) and Kenney and Wissoker (1994). All found empirical evidence of customer discrimination against racial minorities in the US. Our paper builds on the key insights from this literature: we also use the local demographic composition to assess the presence of customer discrimination. However, our approach allows us to go from the evidence of customer discrimination to unemployment and occupation outcomes for the minority workers.

The remainder of the paper is organized as follows : section 2 provides a theoretical test of customer discrimination, section 3 shows empirical results on French data and section 4 concludes.

\section{Test of customer discrimination: Theory}

This section presents a two-sector matching model of unemployment with customer and employer discrimination for workers who only differ by their ethnic group and by their preferences vis-à-vis the different jobs. The model relates the sectorial labor demands, composition of jobs and ethnic groups as well as discriminatory forces to the ethnic differentials in unemployment rates and probability of working in contact with customers. We first expose a benchmark model that relies on simplifying assumptions. We then show that the results of the model are robust to relaxing some of them.

\subsection{The model}

We describe a two-sector static matching model of the labor market for homogeneous workers who only differ by their observable ethnic group and by their preferences vis-à-vis the different jobs. The probability of having located an available job is $m$. Sector 1 is composed of jobs without contact

\footnotetext{
${ }^{6}$ See Kahn (1991) for a literature review of discrimination in professional sports.
} 
with consumers, while sector 2 is composed of contact jobs. With probability $p$, the job is from sector 2 .

All people start non-employed. Job seekers are either African or French native $(j=\mathrm{A}, \mathrm{F}$ respectively). Total population is normalized to 1, with $n$ French natives and 1-n Africans. Search frictions forbid workers from finding a job with certainty and we need to specify the job search process. We start with the assumption whereby search is undirected and so matching is random. By random matching we mean two different things. On the one hand, a worker may apply for jobs in both sectors. This assumption is nonessential as we demonstrate in the robustness section. On the other hand, workers do not perfectly observe the type of employers or consumers. This assumption is important; if it were not true, workers could direct their search to non-discriminatory jobs.

French natives do not suffer from discrimination of any kind. Some French natives may have a disutility towards African employees. We disentangle the disutility that comes from hiring an African employee (employer discrimination) from that which comes from being in contact with an African worker (customer discrimination). Let $a_{e}$ be the proportion of available jobs whose corresponding employer has a taste for discrimination and refuses to hire African employees as a result. We assume that $a_{e}$ is the same in both sectors: the extent of employer discrimination does not vary across sectors. Let also $a_{c}$ be the proportion of available sector- 2 jobs whose customers refuse to interact with an African employee. We assume that $a_{e}$ and $a_{c}$ are proportional to the French native share $n$ in the population. Namely, $a_{e}=\alpha_{e} n$ and $a_{c}=\alpha_{c} n$. Employer discrimination arises when $\alpha_{e}>0$; customer discrimination occurs when $\alpha_{c}>0$.

Job seekers have sector-specific preferences whose distribution may differ between ethnic groups. Let $\phi_{i}^{j}$ denote the proportion of individuals $j$ who accept an offer from sector $i$. If $\phi_{2}^{j}>\phi_{1}^{j}$, then group- $j$ individuals have absolute preferences for contact jobs (sector 2), whereas $\phi_{2}^{F}-\phi_{1}^{F}>\phi_{2}^{A}-\phi_{1}^{A}$ means that French natives have relative preferences for such jobs.

The unemployment rate of French natives is only affected by the global availability of jobs and sectorial preferences. In addition, African workers suffer from both customer and employer discrimination, which affect their employment prospects in specific ways.

The model sets aside wage and profit determination. We implicitly assume that match surplus is shared between employer and wage-earner. Match surplus is negative in three cases: discriminating employer, prejudiced consumers, and when a worker refuses a job offer.

Model outputs. Let $\pi_{i}^{j}$ denote the probability of employment in sector $i$ for a group- $j$ individual. For a group- $j$ individual, let also $q^{j}$ be the probability of employment in sector 2 conditional on being employed, i.e. $q^{j}=\operatorname{Pr}[j$ works in sector $2 \mid j$ works $]$ and $u^{j}$ is the unemployment rate.

For French-native workers, the probability of employment in sector 1 is $\pi_{1}^{F}=(1-p) m \phi_{1}^{F}$ while the probability of employment in sector 2 is $\pi_{2}^{F}=p m \phi_{2}^{F}$. Therefore, the unemployment rate of French natives is

$$
u^{F}=1-\pi_{1}^{F}-\pi_{2}^{F}=1-\left[(1-p) m \phi_{1}^{F}+p m \phi_{2}^{F}\right] .
$$


The conditional probability $q^{F}$ is

$$
q^{F}=\frac{\pi_{2}^{F}}{\pi_{1}^{F}+\pi_{2}^{F}}=\frac{p \phi_{2}^{F}}{(1-p) \phi_{1}^{F}+p \phi_{2}^{F}} .
$$

This probability only depends on the relative supply $p /(1-p)$ of sector-2 jobs and on absolute preference $\phi_{2}^{F} / \phi_{1}^{F}$ of French natives for sector-2 jobs. Neither $u^{F}$ nor $q^{F}$ depend on discriminatory forces, $\alpha_{e} n$ and $\alpha_{c} n$.

We turn to African workers. Africans may be discriminated against, which reduces their employment probabilities. Discrimination may be due to employers (in both sectors) or to consumers (in sector 2 only). The probability of employment in sector 1 is $\pi_{1}^{A}=(1-p) m \phi_{1}^{A}\left(1-\alpha_{e} n\right)$ and it is $\pi_{2}^{A}=p m \phi_{2}^{A}\left(1-\alpha_{e} n\right)\left(1-\alpha_{c} n\right)$ in sector 2. The unemployment rate of Africans is:

$$
u^{A}=1-\left[(1-p) m \phi_{1}^{A}\left(1-\alpha_{e} n\right)+p m \phi_{2}^{A}\left(1-\alpha_{e} n\right)\left(1-\alpha_{c} n\right)\right] .
$$

The conditional probability $q^{A}$ is then given by

$$
q^{A}=\frac{p\left(1-\alpha_{c} n\right) \phi_{2}^{A}}{(1-p) \phi_{1}^{A}+p\left(1-\alpha_{c} n\right) \phi_{2}^{A}} .
$$

Unlike the probability for French natives $q^{F}$, the probability $q^{A}$ decreases with the proportion of French natives in the overall population when there is customer discrimination, i.e. $\partial q^{A} / \partial n<$ 0 . As detailed below, this is what allows us to identify customer discrimination from employer discrimination.

We now discuss more deeply the determinants of the unemployment rate ethnic differential, $\Delta u=u^{A}-u^{F}$, and of the conditional probability ethnic differential, $\Delta q=q^{A}-q^{F}$, given by

$$
\Delta u=m\left[(1-p) \phi_{1}^{F}+p \phi_{2}^{F}-(1-p) \phi_{1}^{A}\left(1-\alpha_{e} n\right)-p \phi_{2}^{A}\left(1-\alpha_{e} n\right)\left(1-\alpha_{c} n\right)\right]
$$

and

$$
\Delta q=\frac{p\left(1-\alpha_{c} n\right) \phi_{2}^{A}}{(1-p) \phi_{1}^{A}+p\left(1-\alpha_{c} n\right) \phi_{2}^{A}}-\frac{p \phi_{2}^{F}}{(1-p) \phi_{1}^{F}+p \phi_{2}^{F}} .
$$

We show that equations (5) and (6) provide a way to identify discrimination, to disentangle consumer from employer discrimination.

Overall discrimination and ethnic unemployment rate differential. The impact of $n$, the local share of French natives, on the unemployment rate differential is given by

$$
\partial \Delta u / \partial n=m\left[(1-p) \phi_{1}^{A} \alpha_{e}+p \phi_{2}^{A}\left[\alpha_{e}\left(1-\alpha_{c} n\right)+\alpha_{c}\left(1-\alpha_{e} n\right)\right]\right] .
$$

An increase in the proportion of French natives raises the unemployment rate differential through two effects: employer discrimination (when $\alpha_{e}>0$ ) lowers job opportunities in both sectors, and customer discrimination (when $\alpha_{c}>0$ ) further deteriorates job chances in sector 2. The sign of the 
impact of the proportion of French natives on the unemployment rate differential provides a test of overall discrimination. We can state our first result as mentioned in the Introduction.

Claim 1. If $\partial \Delta u / \partial n>0$, then $a_{c}(n)>0$ or $a_{e}(n)>0$.

The unemployment rate differential also depends on the proportion of contact jobs and equals:

$$
\partial \Delta u / \partial p=m\left[\phi_{2}^{F}-\phi_{1}^{F}+\phi_{1}^{A}\left(1-\alpha_{e} n\right)-\phi_{2}^{A}\left(1-\alpha_{e} n\right)\left(1-\alpha_{c} n\right)\right] .
$$

The composition of jobs can alter the unemployment rate differential even though no discrimination takes place. If $\alpha_{c}=\alpha_{e}=0$, then the above expression boils down to:

$$
\partial \Delta u / \partial p=m\left[\left(\phi_{2}^{F}-\phi_{1}^{F}\right)-\left(\phi_{2}^{A}-\phi_{1}^{A}\right)\right]
$$

The difference in sectorial labor supply due to differences in preferences between French natives and Africans may cause ethnic unemployment gaps. This phenomenon occurs when French natives have a relative preference for contact jobs. For this reason, identifying the existence of discrimination separately from differences in sectorial labor supply requires us to study either the direct effect of the share of French natives, as shown above, or the interaction between the two forces. Indeed, the model points out the role of the interaction between the proportion of contact jobs and the proportion of French natives:

$$
\partial^{2} \Delta u /(\partial p \partial n)=m\left[\alpha_{e}\left[\phi_{2}^{A}\left(1-\alpha_{c} n\right)-\phi_{1}^{A}\right]+\alpha_{c} \phi_{2}^{A}\left(1-\alpha_{e} n\right)\right]
$$

In the absence of discrimination - that is, $\alpha_{e}=0$ and $\alpha_{c}=0$ - this cross-effect should be zero. The presence of discrimination is evidenced when this crossed partial derivative is nonzero.

Claim 2. If $\partial^{2} \Delta u /(\partial p \partial n) \neq 0$, then $a_{c}(n)>0$ or $a_{e}(n)>0$.

If the interaction term is positive, then three clear-cut cases may occur: (i) there is only customer discrimination, (ii) there is only employer discrimination and Africans have absolute preferences for working in contact jobs, (iii) there are both kinds of discrimination, Africans have absolute preferences for contact jobs $\left(\phi_{2}^{A}>\phi_{1}^{A}\right)$ and the magnitude of the preference force is stronger than that the effect of discrimination in Sector 1, namely

$$
\frac{\phi_{2}^{A}}{\phi_{1}^{A}}>\frac{\alpha_{e}}{\alpha_{e}\left(1-\alpha_{c} n\right)+\alpha_{c}\left(1-\alpha_{e} n\right)} .
$$

Identifying customer discrimination. Consideration of the unemployment rate differential does not allow us to disentangle customer from employer discrimination. In the case of customer discrimination only - that is, $\alpha_{e}=0$ and $\alpha_{c}>0$ - we have

$$
\partial^{2} \Delta u /(\partial p \partial n)=m \phi_{2}^{A} \alpha_{c}>0
$$


However, the derivative is also positive when there is only employer discrimination provided that Africans have absolute preferences for contact jobs. When $\alpha_{c}=0$ and $\alpha_{e}>0$, we have

$$
\partial^{2} \Delta u /(\partial p \partial n)=m\left(\phi_{2}^{A}-\phi_{1}^{A}\right) \alpha_{e}>0
$$

if and only if $\phi_{2}^{A}-\phi_{1}^{A}>0$. The positive impact of employer discrimination is strengthened by the sectorial preference of African native in this case. The sign of the crossed effect, therefore, does not allow us to separately identify the role of customer and employer discrimination.

We need to turn to equation (6) to unambiguously identify customer from employer discrimination. We have

$$
\partial \Delta q / \partial n=-\frac{\alpha_{c} p(1-p) \phi_{1}^{A} \phi_{2}^{A}}{\left[(1-p) \phi_{1}^{A}+p\left(1-\alpha_{c} n\right) \phi_{2}^{A}\right]^{2}} .
$$

This derivative is negative if and only if there is customer discrimination, which leads to our third claim.

Claim 3. $\partial \Delta q / \partial n<0$ if and only if $a_{c}(n)>0$

This results from the fact that employer discrimination is at work in both sectors and does not affect $q^{A}$, the conditional probability of working in sector 2 for Africans. In contrast, customer discrimination affects sector-2 jobs only and therefore does affect $q^{A}$. Moreover, the conditional probability of working in sector 2 for French natives is not affected by either type of discrimination. The proportion of French natives, therefore, negatively affects the differential conditional probability only when there is customer discrimination.

Test strategy. Our test strategy uses the 3 claims. We first estimate the impact of $n$ and $p$ and their interaction on $\Delta u$. If the former is significantly positive, then there is discrimination. The interaction term provides an over-identification test of the presence of ethnic discrimination, in case it is nonzero.

We then estimate the impact of $n$ on $\Delta q$. If negative and there is ethnic discrimination, then there is customer discrimination. If this impact is zero, then there is no customer discrimination; discrimination is only due to employers and the sign of the interaction term tells us for which sector Africans have specific preferences since the interaction term becomes in this case:

$$
\partial^{2} \Delta u /(\partial p \partial n)=m \alpha_{e}\left[\phi_{2}^{A}-\phi_{1}^{A}\right]
$$

\subsection{Robustness of the test strategy}

The test strategy hinges on several assumptions. We now relax some of them or examine alternative settings.

Sector-specific employer discrimination. The link between employer discrimination and the Non-African proportion does not vary across sectors. This assumption can be relaxed: the 
sole requirement is that the intensity of such a link is not stronger in sector 2 than in sector 1 . Otherwise the impact of $n$ on the probability of working in a contact job would not identify customer discrimination.

To see this, suppose that parameter $\alpha_{e}$ actually differs across sectors, with $\alpha_{e}^{1}$ and $\alpha_{e}^{2}$. Claim 1 would still hold because $\partial \Delta u / \partial n>0$ would identify ethnic discrimination. However, Claim 3 would not hold. Indeed, we would have

$$
\Delta q=\frac{p\left(1-\alpha_{c} n\right) \phi_{2}^{A}}{(1-p) \frac{1-\alpha_{e}^{1} n}{1-\alpha_{e}^{2} n} \phi_{1}^{A}+p\left(1-\alpha_{c} n\right) \phi_{2}^{A}}-\frac{p \phi_{2}^{F}}{(1-p) \phi_{1}^{F}+p \phi_{2}^{F}} .
$$

That $\partial \Delta q / \partial n<0$ implies $\alpha_{c}>0$ is now true if $\alpha_{e}^{1} \geq \alpha_{e}^{2}$. Note that we may fail to detect customer discrimination in this case. Indeed, we may observe $\partial \Delta q / \partial n>0$, whereas $\alpha_{c}>0$. However, the empirical finding that $\partial \Delta q / \partial n<0$ would still be a proof of customer discrimination under the identifying restriction that $\alpha_{e}^{1} \geq \alpha_{e}^{2}$.

Statistical discrimination. The basic model abstracts from statistical discrimination, whereas such discrimination is very likely and may vary across sectors. In particular, sector-2 jobs require communication and verbal skills that African workers may lack. ${ }^{7}$ If such skills are imperfectly observable, then employers may be reluctant to hire African workers in such jobs.

It turns out that the consideration of sector-specific statistical discrimination does not affect our test strategy provided that the intensity of statistical discrimination does not depend on the Non-African proportion. Suppose that each African individual suffers from statistical discrimination with probability $s_{i}$ in sector $i$. The probability of getting a job in sector 1 is thus $\pi_{1}^{A}=m(1-p)$ $\phi_{1}^{A}\left(1-s_{1}\right)\left(1-\alpha_{e} n\right)$; similarly, the probability of getting a job in sector 2 is $\pi_{2}^{A}=m p \phi_{2}^{A}\left(1-s_{2}\right)$ $\left(1-\alpha_{e} n\right)\left(1-\alpha_{c} n\right)$. Positing $\tilde{\phi}_{i}^{A}=\phi_{i}^{A}\left(1-s_{i}\right)$, we obtain $\pi_{1}^{A}=m(1-p) \tilde{\phi}_{1}^{A}\left(1-\alpha_{e} n\right)$ and $\pi_{2}^{A}=m p \tilde{\phi}_{2}^{A}$ $\left(1-\alpha_{e} n\right)\left(1-\alpha_{c} n\right)$. The model, therefore, is unchanged and Claims 1 to 3 remain valid.

Unlike employer and customer discrimination, we cannot identify statistical discrimination from ethnic sector-specific preferences. There are two reasons for this outcome. First, employer and customer discrimination explicitly refer to individual prejudice vis-à-vis minority workers. Statistical discrimination is a rational response to a disadvantage that affect minority workers and that cannot be readily observed; such discrimination may vary across sectors, but should not depend on the proportion of the majority group. Second, the reason why employers may discriminate statistically against African workers in contact jobs is because on average they lack the corresponding skills. This lack of skills is also a good reason for such workers generally to prefer non-contact jobs.

Non-Africans and prejudiced individuals. Both customer and employer discrimination are proportional to the share of Non-Africans in the population. The idea is that the rates of prejudiced employers and consumers are constant in the majority group and so there is ethnic discrimination

\footnotetext{
${ }^{7}$ Lang (1986) shows that language differences, confusion and misunderstanding can occur when people from different cultures meet even when one is fluent in the other's language.
} 
if and only if the total percentage of prejudiced agents increases with the size of the majority population.

A natural generalization of our assumption is the following. Let $a_{e}=a_{e}(n)$ and $a_{c}=a_{c}(n)$ denote the proportions of discriminatory jobs due respectively to employers' and customers' tastes. We assume that $a_{e}(n)>0$ if and only if $a_{e}^{\prime}(n)>0$, and, similarly, $a_{c}(n)>0$ if and only if $a_{c}^{\prime}(n)>0$. Claims 1 to 3 are then unchanged.

The generalized assumption means that there is discrimination of some kind if and only if the percentage of discriminatory jobs increases with the majority group at the margin. This case naturally arises when the rate of prejudiced individuals in the majority group is constant or increases with the size of such a group. This is also compatible with cases where prejudice decreases with the size of the majority group. Formally, let $r_{i}(n)$ be the rate of prejudiced individuals among the Non-Africans. Then, $a_{i}(n)=r_{i}(n) n$ and so $a_{i}^{\prime}(n)>0$ is equivalent to $n r_{i}^{\prime}(n) / r_{i}(n)>-1$.

The restriction forbids situations where the Non-African proportion impacts ethnic discrimination with threshold effects. A less restrictive condition would be $a_{i}^{\prime}(n)>0$ only if $a_{i}(n)>0$. Finding $a_{i}^{\prime}(n)>0$ would still provide evidence of ethnic discrimination. However, this condition would no longer be necessary and ethnic discrimination might take place even when $a_{i}^{\prime}(n)=0$. The 'only if' part of Claim 3 would no longer hold, but the 'if' part would still be true.

Obviously, the identifying assumptions must only be true for the range of observed values of $n$. For instance, $n$ varies between 92 and $100 \%$ in our dataset and so we require that employer and customer discrimination increase with the majority proportion on this particular support. Any relationship may emerge outside of this range of values.

Discrimination vs ethnic networks. Many papers use ethnic population density to capture social interactions within the given ethnic group (see, e.g., Conley and Topa (1999); Patacchini and Zenou (2008)). They show that the higher the percentage of a given ethnic group living nearby, the higher the employment rate of this ethnic group. If we translate this idea to our model, the proportion of Non-Africans would be considered as a lack of social networks for African immigrants. We now discuss the implications of this idea for our test strategy.

Social networks affect the job search prospects through two main effects: they help people of the same ethnic group to overcrowd the others in some of the job queues; they provide information on available jobs through word-of-mouth communication for instance. The former effect is already captured by our model specification: positive discrimination within ethnic social networks means that minority workers are actually discriminated against by the majority group and that the extent of discrimination diminishes with the size of the minority group.

To discuss the latter effect, we slightly modify our model. We consider that the main impact of the social network is to increase the job search efficiency. The African job-finding probability is thus $m_{A}=m a(n)$, with $a^{\prime}(\bullet) \leq 0$. The matching probability increases with the number of ethnic ties, and this effect may come on top of ethnic discrimination. The French job-finding probability is $m_{F}=m$. 
The marginal impact of a change in $n$ on the unemployment differential is now:

$$
\begin{aligned}
\partial \Delta u / \partial n= & m\left[(1-p) \phi_{1}^{A} \alpha_{e}+p \phi_{2}^{A}\left[\alpha_{e}\left(1-\alpha_{c} n\right)+\alpha_{c}\left(1-\alpha_{e} n\right)\right]\right] \\
& -\frac{a^{\prime}(n)}{a(n)} u_{A} .
\end{aligned}
$$

The first term is the same as before; it is nonnegative. The second term reflects the fact that the job search efficiency declines with the size of the majority group; it is also nonnegative. So there are two different reasons why the unemployment rate differential may increase with $n$ : workers may be discriminated against, or they may benefit from their ethnic social network. Claim 1 is no longer true as result.

However, the contact job probability $q$ stays unaffected. This probability is conditional on being employed. The factors that affect the overall job-finding probability do not enter the computation. It follows that the consideration of social networks does not affect the rest of the test strategy. Claim 3 still holds: finding $\partial \Delta q / \partial n<0$ still identifies the presence of customer discrimination.

Undirected vs directed search. Search is undirected. Is the test strategy robust to the consideration of directed search? The answer is positive, provided that individuals cannot perfectly observe employer and consumer types. This assumption means that firms do not differentiate jobs by wage so as to induce workers of a group to send their applications towards jobs of a given wage. We here refer once again to the absence of unexplained wage differentials between Africans and French natives.

We slightly amend our model. People differ in taste vis-à-vis different jobs and reach utility level $\mu_{i}$ when they occupy a sector- $i$ job. They must choose a sector first and then send an application for one of the available jobs. Consider a French native and suppose that the matching probability per application is $m_{i}$ in sector $i$. This person chooses to apply for a sector- 1 job if and only if $m_{1} \mu_{1}>m_{2} \mu_{2}$. In other words, people self-select on the basis of their comparative advantage. The proportion of French natives who find a job in sector 1 is $\pi_{1}^{F}=m_{1} \operatorname{Pr}\left[m_{1} \mu_{1}>m_{2} \mu_{2}\right]$.

Back to the initial model, we see that the two probabilities coincide when $m(1-p) \phi_{1}^{F}=m_{1}$ $\operatorname{Pr}\left[m_{1} \mu_{1}>m_{2} \mu_{2}\right]$ and so $\phi_{1}^{F}=\operatorname{Pr}\left[m_{1} \mu_{1}>m_{2} \mu_{2}\right]$. The reduced-form probability $\phi_{1}^{F}$ is now endogenous. The main implication is that we cannot easily identify workers' preferences and job availability because job availability determines the percentage of people who apply for jobs in each sector.

Africans, unlike French natives, take into account the intensity of discrimination in each sector. If they observe employer and consumer types, then they do not apply for discriminatory jobs. The mean employment probability in sector 1 is thus $\pi_{1}^{A}=m_{1} \operatorname{Pr}\left[m_{1} \mu_{1}>m_{2} \mu_{2}\right]$. The only difference with French natives would come from the distribution of sector-specific utility levels. Now, if Africans do not perfectly observe employer and consumer types, then they choose to apply for sector-1 jobs when $m_{1} \mu_{1}\left(1-a_{e}\right)>m_{2} \mu_{2}\left(1-a_{e}\right)\left(1-a_{c}\right)$. Only customer discrimination affects this condition; employer discrimination is the same in both sectors and vanishes as a result. The mean employment 
probability in sector 1 is

$$
\pi_{1}^{A}=m_{1} \operatorname{Pr}\left[m_{1} \mu_{1}>m_{2} \mu_{2}\left(1-a_{c}\right)\right]\left(1-a_{e}\right)
$$

Therefore, $\phi_{1}^{A}=\operatorname{Pr}\left[m_{1} \mu_{1}>m_{2} \mu_{2}\left(1-a_{c}\right)\right]$. Here again we cannot disentangle workers' preferences from job availability; but the novelty comes from the role of customer discrimination that increases the proportion of Africans who apply for jobs in sector 1 .

We now have

$$
\Delta q=\frac{p\left(1-\alpha_{c} n\right) \phi_{2}^{A}(n)}{(1-p) \phi_{1}^{A}(n)+p\left(1-\alpha_{c} n\right) \phi_{2}^{A}(n)}-\frac{p \phi_{2}^{F}}{(1-p) \phi_{1}^{F}+p \phi_{2}^{F}},
$$

where $\phi_{2}^{A}$ decreases with $n$ and $\phi_{1}^{A}$ increases with $n$ whenever there is customer discrimination. The test strategy is unchanged because $\partial \Delta q / \partial n<0$ if and only if there is customer discrimination ${ }^{8}$. However, customer discrimination now has two effects that reinforce each other: at given participation in each sector, it reduces recruitment in sector 2; it also reduces participation in this sector because people expect they will be discriminated against by consumers.

Accounting for job creation. The model leaves aside wage setting and job creation. The main reason why we do not discuss wages is that Africans and French natives seem to receive equal pay when they have similar characteristics. Moreover, a large majority of African immigrants are paid at the minimum wage (See Appendix B). However, the demographic composition of a local labor market could affect the supply of vacancies as well as the relative supply of sector 2 jobs.

Suppose for instance that there is a matching technology with constant returns to scale and that the supply of vacancies responds to job profitability. In all generality, both $m$, the job offer probability, and $p$, the proportion of sector-2 jobs, depend on $n$, the proportion of French natives. That $m$ depends on $n$ does not affect the test strategy. A glance at equation (PD) reveals that the conditional probability of working in a sector- 2 job does not depend on $m$. This is true for both groups of workers. That $n$ affects $p$ modifies equation (PD). Now, a marginal increase in $n$ may impact the conditional probability of working in a contact job through two effects: stronger customer discrimination and a marginal change in the relative supply of contact jobs. The sign of the latter effect is ambiguous.

However, general equilibrium effects induced by the demographic composition of the population are likely to be very small in our dataset. People with African origins amount to $2 \%$ of the total population; they never exceed $8 \%$ of the total population in a given local labor market.

We now turn to micro data to evaluate the quantitative impact of $p$ and $n$.

\footnotetext{
${ }^{8}$ The full model is in Appendix A.
} 


\section{$3 \quad$ Empirical strategy and estimations}

This section tests the former model on French data. Our goal is to estimate equations (6) and (5) on individual data. We linearize such equations and empirically estimate the contribution of forces of discrimination $n$ and $p$ to the individual probability of unemployment $u$ and to the conditional probability of being in contact $q$. The French territory is divided into a partition of local labor markets, characterized by the vector $(p, n, m)$. To use the previous comparative statics exercises, we must also ensure that the other parameters of the model are not location-dependent. Preferences are separately captured for Africans and French natives - African immigrants and French natives in our application - by individual observable characteristics as control variables and the overall effect of the African dummy. This should let us adequately control for parameters $\phi_{1}^{F}, \phi_{2}^{F}, \phi_{1}^{A}$, and $\phi_{2}^{A}$. The matching probability, $m$, similarly affects both ethnic groups. It is controlled for at the local level through local fixed effects. We first introduce our dataset. We then discuss the econometric methodology and present our results.

\subsection{Data}

We use individual data from the 1990 French Census collected by the French National Institute for Statistics and Economic Studies (Insee), which we supplement with the FQP (Formation et Qualification Professionnelle) survey performed in 2003 by Insee to compute the probability of working in a job in contact with consumers for each occupation. The zoning system we consider is composed of 341 mainland "Employment Areas" (hereafter EA). The average employment area is fairly small, covering $1570 \mathrm{~km} 2$, which is equivalent to splitting the U.S. continental territory into over 4700 units. These spatial units are underpinned by clear economic foundations, being defined by the French National Institute of Statistics and Economics (INSEE) so as to maximize the coincidence between residential and working areas. Therefore, EAs are consistent local labor markets; their boundaries are defined so that most of the people who live in the EA also work there. According to the 1990 French Census, more than $80 \%$ of employed individuals work in their EA of residence. The French Census provides information on actual and former citizenship which allows us to identify minority groups. Second-generation African immigrants who automatically obtain French citizenship cannot be identified separately from people whose parents were French. This probably leads to underestimating the scale of discrimination.

We focus on males who have at most a high-school diploma because they are the most exposed to unemployment and the least mobile across $\mathrm{EAs}^{9}$. We only keep males to avoid a number of questions related to family arrangements, residential choices, and female labor market outcomes. We also

\footnotetext{
${ }^{9}$ According to the 1990 French Census, individuals who have at most a high-school diploma are three times more likely to be unemployed than those with a university degree. They also have a lower propensity for mobility: $67 \%$ of high-skilled individuals moved between 1982 and 1990, while the rate falls to $52 \%$ for the low-skilled. Mobility rate is roughly the same between low-skilled French natives and low-skilled African immigrants. However, mobile Africans tend to stay in the same area: only $22 \%$ of low-skilled Africans would move to a different city, while the rate reaches $34 \%$ for low-skilled French natives.
} 
drop from our sample all individuals who were not living in France in 1982, as such newcomers may face specific integration difficulties that could bias our empirical results. Appendix $\mathrm{C}$ details the identification of French natives and African immigrants and defines more precisely our sub-sample of non-newcomers.

The Census details occupations at four-digit level, which unfortunately does not indicate whether the worker is in contact with consumers or not. Therefore, we need external information to compute the fraction of contact jobs in each occupation. FQP is an individual-level database which comes from a survey on a representative sample (39,285 persons) of the French population. The survey is conducted in face-to-face interviews using Computer Assisted Personal Interviewing. Employed individuals were asked whether they were in contact with consumers in their jobs. Working individuals, or people who stopped working less than 5 years ago, answered the question: "Was your job in direct contact with the public?". The answer was declarative: yes or no. FQP also details occupations at the four-digit level. Therefore, we can compute the proportion of contact jobs for each occupation. For statistical reasons we cannot use the four-digit classification: there would be too few persons in a number of occupations. Therefore, we consider the three-digit classification. Turning to the Census, we can attribute to each employee a probability of working in a job in contact with consumers, which is given by the empirical proportion of contact jobs in the worker's occupation. Appendix D details the proportion of contact jobs in each occupation. ${ }^{10}$

Table 1 presents summary statistics for the two sub-populations, African immigrants and French Natives. The first two columns represent the whole sample of both populations and the next four columns correspond to the sub-sample we use in our empirical part. Table 1 shows that African workers are over-exposed to unemployment risk. The overall ethnic unemployment rate gap is about 11 percentage points. Part of the gap is explained by skill differences: first-generation Africans are less likely to reach the highest educational levels than French natives, and are more likely to have no diploma at all. For instance, less than $10 \%$ of them have a high-school diploma (or greater). As expected, the last two lines of the table show that African immigrants are significantly less represented in contact jobs than French natives. Half of French have a job in contact, while this rate falls to one third for Africans. Both the unemployment and the contact gaps between French and Africans are large overall, but also quite variable across locations.

We now explain how the forces of discrimination, the proportion of contact jobs and then the share of Non-African individuals, are computed at the EA level. The proportion of contact jobs is the mean individual probability of being in contact with consumers over all persons working in the EA. ${ }^{11}$ The theoretical model actually considers the proportion of vacant contact jobs. Because of data limitations, we cannot have access to this information. Instead, we compute the proportion of occupied contact jobs. The share of Non-African individuals is measured using the French Census. As

\footnotetext{
${ }^{10}$ One-digit category 1 is excluded since it represents managerial functions and provides too few low-skilled individuals in each three-digit occupation. One-digit category 2 is also excluded because it represents crafts occupations and provides too few wage-earner individuals in each three-digit occupation.

${ }^{11}$ We use work location to determine the relevant EA. For unemployed, we use residential location instead.
} 
Table 1: Summary statistics: Observable characteristics across ethnic groups

\begin{tabular}{|c|c|c|c|c|c|c|}
\hline & \multicolumn{2}{|c|}{ Whole Sample } & \multicolumn{2}{|c|}{ Low-Skilled Men } & \multicolumn{2}{|c|}{ LSM, employed } \\
\hline & Africans & French & Africans & French & Africans & French \\
\hline Unemployment Rate & $\begin{array}{c}18.79 \\
(0.011)\end{array}$ & $\begin{array}{c}7.18 \\
(0.014)\end{array}$ & $\begin{array}{l}19.29 \\
(0.12)\end{array}$ & $\begin{array}{c}7.85 \\
(0.019)\end{array}$ & - & - \\
\hline Employment Rate & $\begin{array}{l}74.39 \\
(0.12)\end{array}$ & $\begin{array}{c}89.05 \\
(0.017)\end{array}$ & $\begin{array}{l}73.86 \\
(0.13)\end{array}$ & $\begin{array}{c}87.39 \\
(0.023)\end{array}$ & - & - \\
\hline Mean age & $\begin{array}{l}42.69 \\
(0.13)\end{array}$ & $\begin{array}{c}38.56 \\
(0.027)\end{array}$ & $\begin{array}{l}43.77 \\
(0.15)\end{array}$ & $\begin{array}{c}39.83 \\
(0.035)\end{array}$ & $\begin{array}{l}43.75 \\
(0.17)\end{array}$ & $\begin{array}{c}39.47 \\
(0.037)\end{array}$ \\
\hline University Diploma & $\begin{array}{c}4.13 \\
(0.054)\end{array}$ & $\begin{array}{c}8.11 \\
(0.015)\end{array}$ & - & - & - & - \\
\hline 2 years graduate Diploma & $\begin{array}{c}2.29 \\
(0.040)\end{array}$ & $\begin{array}{c}6.42 \\
(0.014)\end{array}$ & - & - & - & - \\
\hline HS Diploma & $\begin{array}{c}3.80 \\
(0.052)\end{array}$ & $\begin{array}{c}12.04 \\
(0.018)\end{array}$ & $\begin{array}{c}3.81 \\
(0.057)\end{array}$ & $\begin{array}{c}14.81 \\
(0.025)\end{array}$ & $\begin{array}{c}3.97 \\
(0.068)\end{array}$ & $\begin{array}{c}15.87 \\
(0.028)\end{array}$ \\
\hline Vocational Diploma & $\begin{array}{c}12.16 \\
(0.088)\end{array}$ & $\begin{array}{c}32.32 \\
(0.026)\end{array}$ & $\begin{array}{c}11.8 \\
(0.097)\end{array}$ & $\begin{array}{c}37.62 \\
(0.034)\end{array}$ & $\begin{array}{l}12.30 \\
(0.11)\end{array}$ & $\begin{array}{c}39.38 \\
(0.037)\end{array}$ \\
\hline Junior HS Diploma & $\begin{array}{c}3.02 \\
(0.046)\end{array}$ & $\begin{array}{c}6.82 \\
(0.014)\end{array}$ & $\begin{array}{c}2.89 \\
(0.050)\end{array}$ & $\begin{array}{c}8.04 \\
(0.019)\end{array}$ & $\begin{array}{c}2.97 \\
(0.060)\end{array}$ & $\begin{array}{c}8.33 \\
(0.021)\end{array}$ \\
\hline No Diploma & $\begin{array}{l}74.59 \\
(0.12)\end{array}$ & $\begin{array}{c}34.29 \\
(0.027)\end{array}$ & $\begin{array}{l}81.49 \\
(0.12)\end{array}$ & $\begin{array}{c}39.53 \\
(0.035)\end{array}$ & $\begin{array}{l}80.75 \\
(0.14)\end{array}$ & $\begin{array}{c}36.43 \\
(0.036)\end{array}$ \\
\hline Proportion of being in contact & - & - & - & - & $\begin{array}{l}37.99 \\
(0.18)\end{array}$ & $\begin{array}{c}47.87 \\
(0.046)\end{array}$ \\
\hline $\begin{array}{l}\text { Observations } \\
\text { Proportions }\end{array}$ & 137801 & 3169975 & $\begin{array}{c}110977 \\
80 \% \\
\end{array}$ & $\begin{array}{c}1981213 \\
63 \%\end{array}$ & $\begin{array}{c}81971 \\
59 \% \\
\end{array}$ & $\begin{array}{c}1731433 \\
55 \%\end{array}$ \\
\hline
\end{tabular}

Notes: (i) Sample of the first two columns: All men who participate in the labor market (excluded : enrolled in school, retired, and less than 15); (ii) The sample of the next four columns corresponds to a sub-sample of the first two columns: all low-skilled (who have a high-school diploma or less) men who participate in the labor market, between the ages of 25 and 60; (iii) The sample of the last two columns corresponds to a more restricted sub-sample of the previous columns: all low-skilled (who have an high-school diploma or less) men wage-earners, between the ages of 25 and 60; (iv) The proportion of being in contact is the mean of the individual probability of being in contact with consumers over the sample; (v) Standard errors are in brackets; (vi) The last line represents the number of observations for each column and the corresponding shares of the whole sample in brackets; (vii) Sources: French Census 1990 and FQP 2003.

explained above, our empirical strategy assumes that $\alpha_{e}$ - the proportion of prejudiced employers in the population of Non-Africans - and $\alpha_{c}$ - the proportion of prejudiced consumers in the population of Non-Africans - do not differ across local labor markets. Discrimination intensity, therefore, varies across EAs with the share of Non-Africans, $n$, which can be directly computed from the Census.

Table 2 presents summary statistics of ethnic differentials and discriminatory forces. The unemployment gap between African natives and French natives is relatively large across EAs with an average of 13 percentage points. Both the standard deviation and the coefficient of variation indicate considerable heterogeneity across EAs in terms of ethnic unemployment gaps. The contact gap between African natives and French natives is also relatively high. Both the standard deviation and the coefficient of variation indicate a weaker heterogeneity across EAs in terms of ethnic contact gaps. The proportion of Non-Africans is extremely high: $98 \%$ of the total population is 
Table 2: Summary statistics: Local ethnic differentials and discriminatory forces

\begin{tabular}{lccccc}
\hline & Mean & std dev & Min & Max & Coeff of variation (abs) \\
\hline$\Delta u$ & 12.8 & 9.7 & -17.9 & 40.4 & 0.75 \\
$\Delta q$ & -11.2 & 5.7 & -26.1 & 4.2 & 0.51 \\
\%Non-Africans & 97.9 & 1.8 & 92.0 & 99.9 & 0.018 \\
\%Contact & 48.8 & 6.2 & 29.9 & 61.2 & 0.13 \\
\%Contact.\%Non-Africans & 4770 & 570 & 2990 & 6006 & 0.12 \\
\hline
\end{tabular}

Notes: (i) Reported statistics give equal weight to each EA; (ii) $\Delta u$ and $\Delta q$ are the differences between Africans and French in the unemployment rate and the probability of being in contact with consumers. These are computed on EAs that contain at least 50 African immigrants; (iii) Sources: 1990 French Census, 2003 FQP survey and authors' computations.

Non-African on average. Both the standard deviation and the coefficient of variation of the share of Non-Africans are small. Such a weak heterogeneity across EAs is partly due to the definition of Africans in the French Census. The African group only contains first-generation Africans and, therefore, underestimates the total population of Africans. We show below that such a variability is large enough to identify discrimination and prove its relatively large magnitude. On average $50 \%$ of unskilled jobs are in contact with consumers. This proportion is relatively dispersed across EAs, with a coefficient of variation which is almost 7 times higher than the coefficient of variation of the proportion of Non-Africans.

Figure 1 maps the residential location of African immigrants across EAs. African immigrants are concentrated in dense areas, especially in the Paris region and in the South East. This location bias is possibly explained by the unequal distribution of public housing. Most of the public housing (or HLM: Habitations à Loyer Modéré) supply is located in the deprived outskirts of large cities. According to the 1990 French Census, African immigrants are overrepresented in the HLM complex. Near $50 \%$ of African immigrants live in HLM, compared to about $15 \%$ of French natives.

Figure 2 maps the spatial distribution of low-skilled contact jobs across EAs. It shows that these unskilled jobs are concentrated in dense EAs, especially in the Paris region and in areas which attract tourists: South East, South West and Brittany. In these areas, the proportion of low-skilled jobs in services (restaurants, hotels, shops) is disproportionately high.

\subsection{Econometric methodology}

Discriminatory forces are measured at the EA level. One difficulty lies in disentangling the impact of discriminatory forces from other effects that take place at the same geographic level. To circumvent this difficulty, we adopt a two-step procedure appealing to EA fixed effects. In the first step, we regress individual labor market outcomes on a set of individual characteristics (among which a dummy variable for Africans), on EA fixed effects, and on EA effects interacted with an African 
Figure 1: Proportion of African immigrants by Employment Area

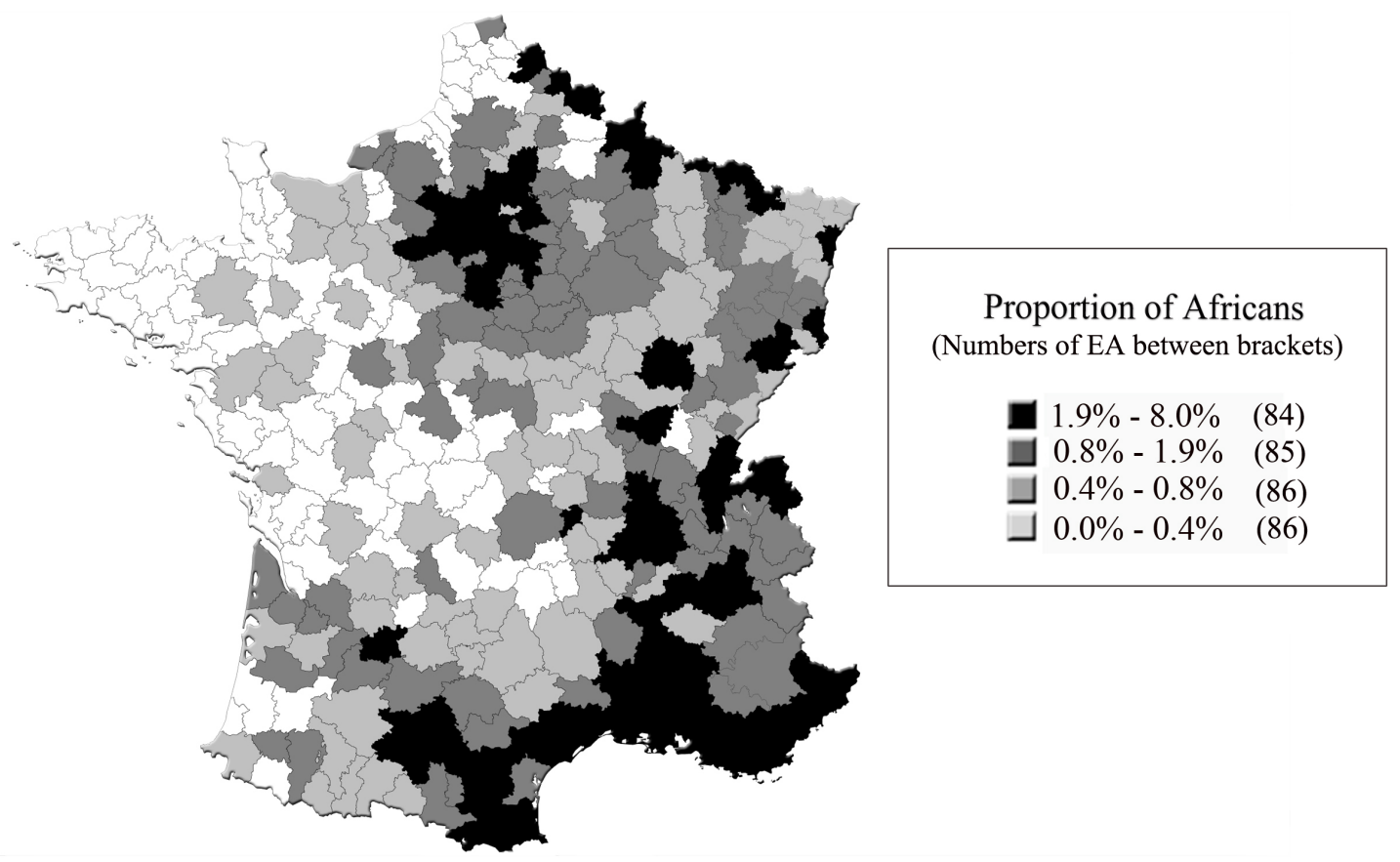

dummy that takes the value one if the individual is African and 0 otherwise. ${ }^{12}$ In the second step, we regress the estimated EA effects specific to the Africans on discriminatory forces.

First step. First-step specifications can be written as:

$$
\begin{gathered}
u_{i}^{*}=\beta_{0}+\beta_{1} X_{i}^{1}+\beta_{2} A f r_{i}+\beta_{3} A f r_{i} \cdot X_{i}^{1}+\psi_{k(i)}^{1}+\varphi_{k(i)}^{1} \cdot A f r_{i}+\varepsilon_{1 i} \\
q_{i}=\gamma_{0}+\gamma_{1} X_{i}^{2}+\gamma_{2} A f r_{i}+\gamma_{3} A f r_{i} \cdot X_{i}^{2}+\psi_{k(i)}^{2}+\varphi_{k(i)}^{2} \cdot A f r_{i}+\rho \sigma_{2} \widehat{\lambda}_{i}+\varepsilon_{2 i}
\end{gathered}
$$

where $u_{i}^{*}$ is a latent variable that captures the probability of being unemployed for individual $i$, $q_{i}$ is its probability of being in contact with consumers, and $k(i)$ the corresponding EA, $X_{i}$ is the vector of observed individual characteristics, $A f r_{i}$ is a dummy variable equal to 1 for Africans and 0 otherwise, and $\varepsilon_{1 i}$ and $\varepsilon_{2 i}$ are mean-zero stochastic error terms representing the influence of omitted variables ${ }^{13}$.

The coefficients on the EA-African interactions $\varphi_{k}^{1}$ and $\varphi_{k}^{2}$ allow us to compute estimates of both ethnic unemployment and contact gaps in each EA adjusted for (i) EA factors that affect the

\footnotetext{
${ }^{12}$ We include an interaction term for every location, except one. Estimating a coefficient for every location automatically gives an estimate of the standard error for each coefficient, which we use to correct for heteroskedasticity in the second step.

${ }^{13}$ Explanatory variables are age, age squared, and four educational dummy variables. For the unemployment equation, we add exclusion variables: marital status and the presence of children. For the contact equation, we add occupation dummies at one-digit level.
} 
Figure 2: Proportion of low-skilled jobs in contact with consumers by Employment Area

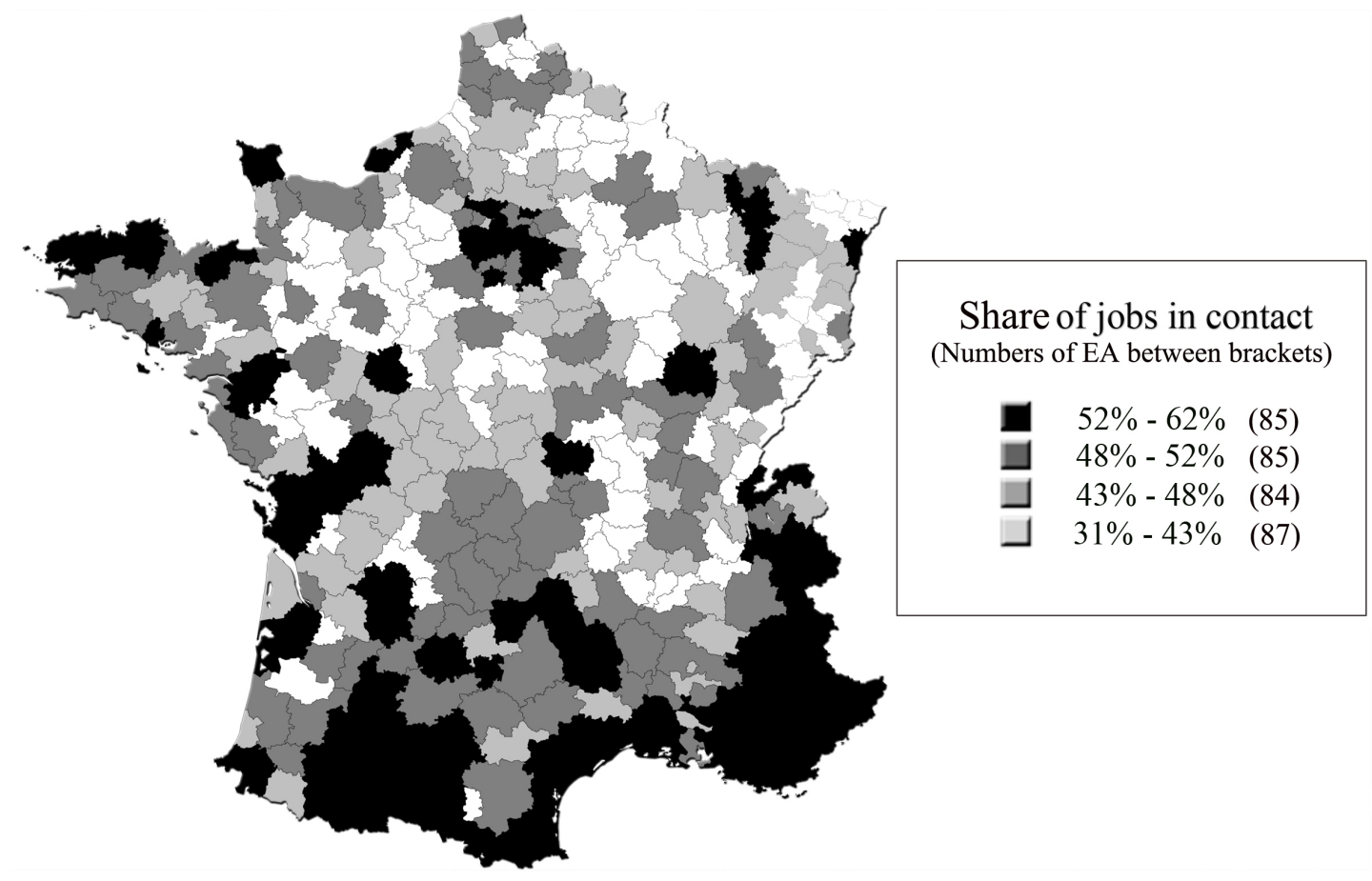

unemployment and contact levels of all local individuals in a similar way and (ii) for ethnic differences in individual characteristics and in the returns of these characteristics. The set of coefficients $\left\{\psi_{k}^{1}\right\}$ provides estimates for the impact of the ratio of available jobs to job-seekers in each EA. Similarly, the set of coefficients $\left\{\psi_{k}^{2}\right\}$ provides proxies for the proportion of contact jobs in available jobs. Note that in equation (19), the African unemployment level in EA $k$ is captured by the coefficient $\psi_{k}^{1}+\varphi_{k}^{1}$, while the French one is captured by $\psi_{k}^{1}$. In equation (20), the African contact level in EA $k$ is captured by the coefficient $\psi_{k}^{2}+\varphi_{k}^{2}$, while the French contact level is captured by $\psi_{k}^{2} \cdot{ }^{14}$

Second step. Following our theoretical framework, we regress the estimated coefficients $\varphi_{k}^{1}$ and $\varphi_{k}^{2}$ on the various discriminatory forces ${ }^{15}$. In the unemployment regression, discriminatory forces are the local shares of Non-Africans in the EA, \%Non-Africans ${ }_{k}$, and of jobs in contact, \% Contact . $_{\text {. }}$ As the model highlights, the interaction of these forces must also be introduced:

$$
\hat{\varphi}_{k}^{1}=\delta_{0}+\delta_{1} \% \text { Non }- \text { Africans } k+\delta_{2} \% \text { Contact }_{k}+\delta_{3} \% \text { Non }- \text { Africans }_{k} . \% \text { Contact }_{k}+v_{1 k}
$$

\footnotetext{
${ }^{14}$ Sample selection bias may affect the estimation of model (20). Our theory predicts that sector-specific preferences and consumer discrimination affect both the unemployment probability and the probability of working in a job in contact with consumers. To correct for sample selection bias, we follow Heckman (1979) and include the inverse of Mills' ratio $\widehat{\lambda}_{i}$ in equation (20). Our dual model is identified thanks to the introduction into the selection equation (19) of variables that are intended to have an impact on the unemployment probability but not directly on the probability of contact with consumers. The variables are the marital status and the presence of children.

${ }^{15} \mathrm{EAs}$ with less than 50 Africans are dropped in regression (21) and EAs with less than 50 African workers are dropped in regression (22).
} 
In the contact equation, the $\varphi_{k}^{2}$ estimates must be regressed on the sole force share of Non-Africans:

$$
\hat{\varphi}_{k}^{2}=\omega_{0}+\omega_{1} \% \text { Non }- \text { Africans } k+v_{2 k}
$$

\subsection{Results}

We first comment on the estimates of our four-equation model, then use them to quantify the magnitude of the discriminatory forces on ethnic unemployment and contact gaps.

First-step regressions. Table 3 presents results for the unemployment equation (19), while Table 4 presents results for the contact probability equation (20). ${ }^{16}$ Individual characteristics provide expected results in both regressions. In the unemployment regression, a higher education increases the probability of being employed. For each education level, returns to education for Africans are lower. Potential experience has a positive and concave impact on employment probability. Married men are less unemployed than single men (the reference situation). In the contact regression, for both groups, a higher education increases the probability of being in contact with consumers. However, when occupations are included, men with high-school diplomas are less in contact than men with no diploma (the reference situation). The probability of being in contact with consumers increases with age for French while it decreases for Africans. ${ }^{17}$ EA fixed-effects capture both the overall local differences across EAs in the levels of unemployment and of contact jobs. Appendix F includes figures depicting the fixed-effects of the unemployment regression against the EA unemployment rate, and fixed-effects of the contact job regression against the contact job proportion in each EA. Such figures visually depict that for both ethnic groups location is a key determinant of employment and contact probabilities even when individual characteristics and group-specific returns to individual characteristics are controlled for. Local effects interacted with the African dummy capture the relative unemployment and contact rates of African immigrants. Tables 3 and 4 report summary statistics for EA fixed-effects. The estimated impacts are very large. An African moving from the EA at the first decile to the EA at the last decile of fixed effects would increase his unemployment rate by around $20 \%$ points and increase his contact probability by 10 to $13 \%$ points.

Second-step regressions. Table 5 presents second-step regression results. ${ }^{18}$ Table 5 reports

\footnotetext{
${ }^{16}$ Appendix E provides full first-step regressions.

${ }^{17}$ The Mills' ratio, $\lambda$, is significantly negative, which suggests that the error terms in the selection equation and in the contact regression are negatively correlated. Unobserved factors that make participation more likely tend to be associated with a lower rate of contact with consumers. There is selection since $\chi^{2}$ value for $\rho$ is statistically significant.

${ }^{18}$ Given that the second-step dependent variables are estimated in the first-step, errors of the second-step regressions $v_{1 k}$ are heteroskedastic. Following Card and Krueger (1992), observations are weighted by the inverse of the squared standard error from the first step to take into account this measurement error.
} 
Table 3: Probability of unemployment: first-step results

\begin{tabular}{|c|c|c|c|c|}
\hline & $\begin{array}{l}\text { OLS } \\
(1)\end{array}$ & $\begin{array}{c}\text { Probit } \\
(2)\end{array}$ & $\begin{array}{c}\text { OLS } \\
(3)\end{array}$ & $\begin{array}{l}\text { Probit } \\
\text { (4) }\end{array}$ \\
\hline Individual controls & yes & yes & yes & yes \\
\hline African & $\begin{array}{c}0.83^{a} \\
(0.013)\end{array}$ & $\begin{array}{c}0.71^{a} \\
(0.013)\end{array}$ & $\begin{array}{c}0.66^{a} \\
(0.054)\end{array}$ & $\begin{array}{c}0.51^{a} \\
(0.096)\end{array}$ \\
\hline $\begin{array}{l}\text { EA fixed effects } \\
\text { Inter-decile } \\
\#>0 \text { at } 5 \% \\
\#<0 \text { at } 5 \% \\
\text { EA fixed effects X 'African' } \\
\text { Inter-decile } \\
\#>0 \text { at } 5 \% \\
\#<0 \text { at } 5 \%\end{array}$ & & & $\begin{array}{c}{[-0.048-0.071]} \\
141(47 \%) \\
153(52 \%) \\
\\
{[-0.061-0.13]} \\
118(40 \%) \\
140(47 \%)\end{array}$ & $\begin{array}{c}{[-0.056-0.085]} \\
136(46 \%) \\
159(54 \%) \\
\\
{[-0.079-0.14]} \\
125(42 \%) \\
135(46 \%)\end{array}$ \\
\hline Observations & $1,411,300$ & 1411,300 & $1,411,300$ & $1,411,300$ \\
\hline $\mathrm{R}^{2}$ & 0.10 & 0.11 & 0.12 & 0.13 \\
\hline
\end{tabular}

Notes: (i) Standard errors in brackets; (ii) Significance levels : a: 1\%, b: 5\%, c: 10\% ; (iii) Sample: low-skilled men between 25 and 60; (iv) Columns (1) and (3) are a linear probability model and columns (2) and (4) a probit model. (v) Individual controls are age, a quadratic in age, education dummies, marital status, presence of children. All of these are also interacted with the demographic group; (vi) For fixed-effects, significance is calculated relative to the national mean.

Table 4: Probability of being in contact among employees: first-step results

\begin{tabular}{lcccc} 
& OLS & OLS & OLS & OLS \\
& $(1)$ & $(2)$ & $(3)$ & $(4)$ \\
\hline Controls : age, diploma & yes & yes & yes & yes \\
Controls : occupations & & yes & & yes \\
African & $-0.078^{a}$ & $-0.036^{a}$ & $-0.11^{a}$ & $-0.052^{a}$ \\
& $(0.00052)$ & $(0.00047)$ & $(0.00052)$ & $(0.00048)$ \\
EA fixed effects & & & {$[-0.040-0.083]$} & {$[-0.029-0.048]$} \\
Inter-decile & & $157(53 \%)$ & $163(55 \%)$ \\
$\#>0$ at 5\% & & $138(47 \%)$ & $132(45 \%)$ \\
$\#<0$ at 5\% & & {$[-0.056-0.062]$} & {$[-0.049-0.054]$} \\
EA fixed effects X 'African' & & & $137(46 \%)$ & $137(46 \%)$ \\
Inter-decile & & & $112(38 \%)$ & $106(36 \%)$ \\
$\#>0$ at 5\% & & & $1,153,600$ & $1,153,600$ \\
$\#<0$ at 5\% & & & 0.084 & 0.24 \\
\hline Observations & $1,153,600$ & $1,153,600$ & 0.22 & \\
$\mathrm{R}^{2}$ & 0.04 & & & \\
\hline
\end{tabular}

Notes: (i) Standard errors in brackets; (ii) Significance levels : a: 1\%, b: 5\%, c: 10\% ; (iii) Sample: low-skilled wage-earning men between 25 and 60; (iv) Specifications are corrected for sample selection bias, using column (2) of Table 3 to compute the inverse of Mill's Ratio; the Wald test indicates the correlation coefficient between error terms is significant at $1 \% ;(\mathrm{v})$ Individual controls are age, a quadratic in age and education dummies. All of these are also interacted with the demographic group; (vi) For fixed-effects, significance is calculated relative to the national mean.

the estimated effects from a first-step linear probability model (column 3, Table 3$)^{19}$. The share

\footnotetext{
${ }^{19}$ In Appendix G, Table 15 reports the estimated effects from a probit model.
} 
of Non-Africans has a significant negative effect on African employment prospects ${ }^{20}$. Following our model, this result shows there is ethnic discrimination in the French labor market. It is interesting to note that the share of contact jobs has a small explanatory power when introduced alone, whereas it increases considerably the explanatory power of the model when introduced next to the share of Non-Africans. This is probably due to its negative correlation with this share. When introduced alone, the model is mis-specified, the share of contact jobs captures two effects going in opposite directions, and therefore explains little. Column (4) suggests that part of the effect of the proportion of Non-Africans arises from its interaction with the proportion of contact jobs, with an explanatory power even greater than in previous columns. According to the model, our favored interpretations of the positive impact of the interaction term is that either there is only customer discrimination, or there is only employer discrimination and Africans have absolute preferences of working in contact jobs, or there are both kinds of discrimination, Africans have absolute preferences for contact jobs, and the preference differential is stronger than the effect of employer discrimination in Sector 1.

Using Table 5, the estimated coefficient allows us to compute that a one-standard-deviation increase in the proportion of contact jobs increases the adjusted ethnic unemployment gap by .15-.25 of its standard deviation. A one-standard-deviation increase in the Non-African proportion widens the ethnic unemployment gap by .20-.25 of its standard deviation. The figures for estimates reported in column (4) where we consider the interaction term denote a large effect: a one-standard-deviation increase in the Non-African proportion raises the adjusted gap by .16-.47 of its standard deviation (at shares of contact jobs of $45 \%$ and $63 \%$, respectively). The effect of the share of prejudiced individuals is much stronger in areas where the proportion of contact-jobs is significantly high. Table

Table 5: Second-step regression results on the probability of unemployment - OLS in first step

\begin{tabular}{lcccc} 
& \multicolumn{3}{c}{ Adjusted Unemployment Gap } \\
\cline { 2 - 5 } & $(1)$ & $(2)$ & $(3)$ & $(4)$ \\
\hline \%Contact & $0.0023^{a}$ & & $0.0035^{a}$ & $0.0037^{a}$ \\
\%Non-Africans & $(0.00085)$ & & $(0.00086)$ & $(0.0011)$ \\
\%Contact $\%$ Non-Africans & & $0.014^{a}$ & $0.019^{a}$ & $0.016^{a}$ \\
Constant & & $(0.0040)$ & $(0.0041)$ & $(0.0055)$ \\
& & & & $0.0013^{b}$ \\
Observations & 0.044 & $-1.27^{a}$ & $-1.88^{a}$ & $(0.00061)$ \\
$\mathrm{R}^{2}$ & $(0.042)$ & $(0.39)$ & $(0.41)$ & 4.43 \\
& 294 & 294 & 294 & $(3.04)$ \\
\hline
\end{tabular}

Notes: (i) Weighted least squares regressions using the inverse of estimated variance of coefficients from first-step regression reported in Table 3 as weights; (ii) Standard errors in brackets. Significance levels : a: 1\%, b: 5\%, c: $10 \%$ ; (iii) Columns are estimated using a first-step linear probability model in Table 4.

6 reports second-step regression results from the first-step contact regression. The share of Non-

\footnotetext{
${ }^{20}$ Appendix $\mathrm{H}$ provides single-step regressions in distinguishing immigrants from North African and those from sub-Saharan Africa. Results are qualitatively similar for both groups.
} 
Africans has a significant negative effect on the adjusted ethnic differential probability of working in a contact job. Following our theoretical model, this negative impact can be interpreted as evidence of customer discrimination against African immigrants in the French labor market. Controlling or not for occupations on top of education in the first step barely affects the conclusion. As robustness check, we nonetheless run a single-stage estimation for both outcomes and find qualitatively similar results (see Appendix I).

Table 6: Second-step regression results on the contact probability

\begin{tabular}{lcc}
\cline { 2 - 3 } & \multicolumn{2}{c}{ Adjusted Contact Gap } \\
\cline { 2 - 3 } & $(1)$ & $(2)$ \\
\hline \%Non-Africans & $-0.00403^{a}$ & $-0.00398^{a}$ \\
Constant & $(0.00104)$ & $(0.00116)$ \\
& $0.419^{a}$ & $0.405^{a}$ \\
Observations & $(0.100)$ & $(0.112)$ \\
Pseudo-R & 278 & 278 \\
& 0.0516 & 0.410 \\
\hline
\end{tabular}

Notes: (i) Weighted least squares regressions using the inverse of estimated variance of coefficients from first-step regression reported in Table 4 as weights; (ii) Standard errors in brackets. Significance levels : a: 1\%, b: 5\%, c: 10\% ; (iii) Columns (1) and (2) are estimated using columns (3) and (4) of the first-step regressions in Table 4, respectively, i.e. controlling or not for occupations on top of education.

\subsection{Robustness checks and limitations of the empirical strategy}

Results presented in Tables 5 and 6 provide evidence of customer discrimination in contact jobs. However, our empirical strategy might face some empirical issues.

\section{Fixed values of $\alpha_{e}$ and $\alpha_{c}$ across local labor markets}

Our theoretical model assumes that $\alpha_{e}$ and $\alpha_{c}$ are constant across local labor markets. By contrast, the proportion of Non-Africans, $n$, and the proportion of contact jobs, $p$, vary from one local labor market to another. As a result, the intensity of discrimination only varies with $n$ and $p$. This assumption hinges on the idea that the level of prejudice among French natives is uniform on the French territory.

It is not necessarily true. Unfortunately, unlike the US with the General Social Survey, we cannot compute a measure of racial intolerance at the local level. Instead, we control for the vote share for the Front National in both legislative (1988 and 1993) and presidential (1988, 1995, 2002 and 2007) elections as a direct measure of hypothetic anti-immigrant sentiment of French, in our estimations. The Front National is the far-right party in France. Our theoretical model shows the number of discriminating individuals increases with the share of Non-Africans at given prejudiced proportion in the population. Hence, controlling for this share in our estimations seems natural. Our coefficients of interest are still highly significant and support evidence of consumer discrimination against African immigrants. 
Using the ethnic composition of individuals instead of the genuine rate of ethnic prejudice can lead to bias our results if these two shares are positively correlated. At first sight, this is the case. The vote share of $\mathrm{FN}$ is positively correlated to the share of immigrants with a correlation coefficient of 0.39. We could easily explain this phenomenon whereby the level prejudice increases with the number of Africans in the area as the majority group may feel more threatened in areas where Africans are a large part of the population. If this explanation is true, it therefore weakens the predictions of our theoretical model as we consider the share of Non-Africans as source of discrimination. This causal relationship is not clearly established. Indeed, the effect of the ethnic composition on the vote share of $\mathrm{FN}$ is no more positively significant when some composition effects (like the shares of unemployment and of unskilled individuals) are included in regressions. ${ }^{21}$

\section{Spatial sorting}

So far, we have neglected residential choices. There are strong reasons to consider that workers, and especially Africans, are not very mobile across local labor markets ${ }^{22}$. On the other hand, they probably do not allocate randomly across all possible locations. Therefore, endogeneity concerns due to reverse causality may affect the relevance of our estimates. African residential choices may respond to discriminatory forces. Africans would choose to locate in EAs characterized by a low ethnic unemployment rate differential or a low proportion of contact jobs. The OLS estimate of the coefficient on the proportion of Non-Africans would over-estimate the effect of discrimination due to such endogenous residential behavior ${ }^{23}$.

We address this problem by using an instrumental variable approach based on the 1968 Census and on some geographical variables. In order to perform meaningful over-identification tests, we need a large number of instruments different in their nature. For the ethnic unemployment gap, we consider the following variables: the share of agriculture and industry sectors, the proportion of homeowners, the proximity to the sea and population density. Beyond statistical tests, the choice of such instruments is based on the following considerations. The African population pattern today

\footnotetext{
${ }^{21}$ This same positive relationship between the share of blacks and the level of prejudice is also observed in the US. Using both General Social Survey and Census data, we observe blacks live disproportionately in regions in which racial prejudice is the most severe (See also Charles and Guryan (2008)). This pattern is caused in large part by historical reasons. Sundstrom (2007) shows that counties where blacks are a large share of the workforce used to be some plantation farming areas and were characterized by a strong tradition of hierarchical race relations where voters expressed segregationist preferences in the 1948 presidential election. Slave states (States in which slavery was legal in 1861 just before it was abolished by the 13th Amendment of the US Constitution in 1865) are stronger predictors of racial prejudice than the share of blacks at the state level. Hence, the positive relationship between prejudice and the share of blacks reflects historical patterns rather than a purely causal effect.

${ }^{22}$ Some papers examine the relevance of the Spatial Mismatch Hypothesis (due to Kain (1968)) for the French labor market. Gobillon and Selod (2007) and Gobillon et al. (2011) show that urban segregation affects unemployment risk. Unlike our paper, they do not specifically focus on minority workers, whereas the residential mobility of this population is constrained and there is evidence of discrimination in the housing market (see, e.g., Combes et al. (2011)).

${ }^{23}$ The sorting of immigrants can also be driven by their skills. If the less skilled immigrants locate in EAs that contain a small proportion of immigrants, a significant and large unemployment gap could be spuriously attributed to discrimination. In our case, EAs characterized by a high share of immigrants are also those which contain a large share of unskilled immigrants. The correlation coefficient between the share of African immigrants and the proportion of African with no diploma is of 0.365 at the EA level. Hence, this sorting effect is likely to bias downwards our test of discrimination.
} 
reflects the industrial fabric of that period of time and Africans' preference for certain sectors. A further inducement to settle would have been the housing conditions available in certain areas. In what follows, we provide necessary over-identification and weak instrument tests. 2SLS results are

Table 7: Second-step regression results on the probability of unemployment - 2SLS

\begin{tabular}{|c|c|c|c|c|c|c|}
\hline & $\begin{array}{l}\text { OLS } \\
(1)\end{array}$ & $\begin{array}{l}\text { IV } \\
(2)\end{array}$ & $\begin{array}{l}\text { IV } \\
(3)\end{array}$ & $\begin{array}{c}\text { OLS } \\
(4)\end{array}$ & $\begin{array}{l}\text { IV } \\
(5)\end{array}$ & $\begin{array}{l}\text { IV } \\
(6)\end{array}$ \\
\hline$\%$ Contact & $\begin{array}{c}0.0035^{a} \\
(0.00086)\end{array}$ & $\begin{array}{c}0.00382^{a} \\
(0.00100)\end{array}$ & $\begin{array}{c}0.00359^{a} \\
(0.000949)\end{array}$ & $\begin{array}{l}0.0037^{a} \\
(0.0011)\end{array}$ & $\begin{array}{c}0.00396^{b} \\
(0.00172)\end{array}$ & $\begin{array}{c}0.00394^{b} \\
(0.00162)\end{array}$ \\
\hline$\%$ Non-Africans & $\begin{array}{l}0.019^{a} \\
(0.0041)\end{array}$ & $\begin{array}{c}0.0148^{b} \\
(0.00697)\end{array}$ & $\begin{array}{c}0.0108^{c} \\
(0.00637)\end{array}$ & $\begin{array}{c}0.016^{a} \\
(0.0055)\end{array}$ & $\begin{array}{c}0.00284 \\
(0.0118)\end{array}$ & $\begin{array}{c}-0.00206 \\
(0.00962)\end{array}$ \\
\hline$\%$ Contact $\times \%$ Non-Africans & & & & $\begin{array}{l}0.0013^{a} \\
(0.00061)\end{array}$ & $\begin{array}{c}0.00235^{c} \\
(0.00128)\end{array}$ & $\begin{array}{c}0.00307^{a} \\
(0.00113)\end{array}$ \\
\hline Constant & $\begin{array}{c}-1.88^{a} \\
(0.41)\end{array}$ & $\begin{array}{l}-1.49^{b} \\
(0.71)\end{array}$ & $\begin{array}{r}-1.078^{c} \\
(0.64)\end{array}$ & $\begin{array}{c}4.43 \\
(3.04)\end{array}$ & $\begin{array}{l}10.78 \\
(6.86)\end{array}$ & $\begin{array}{l}14.90^{b} \\
(5.97)\end{array}$ \\
\hline J-stat P-Value & & 0.193 & 0.229 & & 0.783 & 0.276 \\
\hline Cragg-Donald & & 61.40 & 36.38 & & 26.02 & 24.71 \\
\hline Shea $\mathrm{R}^{2}$ [\%Non-Africans] & & 0.401 & 0.452 & & 0.428 & 0.451 \\
\hline Shea $\mathrm{R}^{2}[\%$ Contact $\times \%$ Non-Africans] & & & & & 0.478 & 0.484 \\
\hline Observations & 294 & 294 & 294 & 294 & 294 & 294 \\
\hline
\end{tabular}

Notes: (i) Column (1) reports OLS results from Table 5, column (3); In column (2), the proportion of Non-Africans in 1990 is instrumented by the proportion of homeowners in 1968 and the proximity to the sea/ocean (Atlantic and Mediterranean); In column (3), the proportion of Non-Africans in 1990 is instrumented by the share of workers in the agriculture and industry sectors across EAs in 1968, the proximity to the sea/ocean (Atlantic and Mediterranean) and population density ; Column (4) reports OLS results from Table 5, column (4); In columns (5) and (6), the proportion of Non-Africans and the interaction variable are instrumented by the same variables as in columns (2) and (3), respectively and their interactions with the share of jobs in contact with consumers. (ii) Standard errors in brackets. Significance levels : a: $1 \%$, b: $5 \%$, c: $10 \%$.

presented in Table 7. Columns (1) and (4) report OLS estimates, whereas columns (2), (3), (5) and (6) report IV estimates. The magnitude and significance of the parameters are very slightly altered. When the interaction variable is included in columns (5) and (6), the direct effect \% Non-Africans is no more significant; however the instrumented interaction effects are even larger than with OLS and still positively significant. The lower part of Table 7 presents two key instrument tests: an overidentification test (Hansen J Statistic) for the exogeneity of the instruments, and a weak instrument test based on Stock and Yogo (2002). In all four of these columns, over-identification tests do not reject the null hypothesis that the instruments are exogenous at the $10 \%$ level. The Cragg-Donald statistic Cragg and Donald (1997) is also well above the Stock and Yogo's threshold corresponding to the $10 \%$ p-value. On top of the intuitive arguments displayed above, these tests corroborate the validity of our instrumental strategy.

We similarly proceed for the differential probability of working in contact with consumers. Unfortunately we cannot consider the sectorial composition of jobs as a valid instrument variable. We manage to instrument the share of Non-Africans in 1990 with variables related by the characteristics of the family structure, of the local housing markets and of geographical factors. We use the share of 
families with more than 6 members, the share of small buildings (less than 20 dwellings), the share of homeowners, all three computed in 1968, and some geographical variables like the proximity to the sea/ocean, to borders and population density. 2SLS results are presented in Table 8. Column (1) reproduces the OLS estimates, whereas columns (2) to (4) show the IV estimates. The coefficients of the instrumented variable are larger (in absolute value), and still negatively significant. The over-identification and weak instrument tests continue to support the validity of the instruments.

Table 8: Second-step regression results on the probability of contact - 2SLS

\begin{tabular}{lcccc}
\cline { 2 - 5 } & OLS & IV & IV & IV \\
\cline { 3 - 5 } \%Non-Africans & $(1)$ & $(2)$ & $(3)$ & $(4)$ \\
\cline { 2 - 5 } Constant & $-0.00403^{a}$ & $-0.00785^{b}$ & $-0.00869^{a}$ & $-0.00586^{b}$ \\
& $(0.00104)$ & $(0.00333)$ & $(0.00316)$ & $(0.00267)$ \\
& $0.419^{a}$ & $0.795^{b}$ & $0.879^{a}$ & $0.600^{b}$ \\
J-stat P-Value & $(0.100)$ & $(0.327)$ & $(0.310)$ & $(0.261)$ \\
Cragg-Donald & & 0.237 & 0.372 & 0.283 \\
Shea R R\%Non-Africans] & & 65.35 & 78.57 & 13.55 \\
Observations & 278 & 0.436 & 0.433 & 0.382 \\
\hline
\end{tabular}

Notes: (i) Column (1) reports OLS results from Table 6, column (1); In column (2), the 1990 proportion of NonAfricans is instrumented by the share of homeowners in 1968 and the proximity to the sea/ocean ; In column (3), the 1990 proportion of Non-Africans is instrumented by the share of homeowners in 1968 and population density ; In column (4), the 1990 proportion of Non-Africans is instrumented by the proportion of families with more than 6 members, the spatial distribution of small buildings (less than 20 dwellings) in 1968 and the proximity to borders ;

(ii) Standard errors in brackets. Significance levels : a: $1 \%, \mathrm{~b}: 5 \%, \mathrm{c}: 10 \%$. 


\section{Computation of the contact job probability}

Strictly speaking we do not observe whether individuals work in a contact job or not. We rather compute the occupation-specific probability of having a contact job. We do so from the three-digit classification of occupations available in both the Census and the FQP survey. The main drawback of this variable is due to the fact that even in high-contact-rate occupations, African workers might not interact with consumers. Let us consider two occupations that are particularly well represented among African workers. Occupation ' 561 ' contains waiters, cooks, kitchen helpers, hotel desk clerks, maids and housekeeping cleaners. Occupation '631' contains electrical and electronics repairers/installers, electronic equipment installers and repairers (home appliance). In occupation ' 561 ', $85 \%$ of French-native workers are in contact with consumers, whereas this rate falls to $61 \%$ for first-generation African immigrants. Similarly, in occupation '631', $76 \%$ of the French natives are in a contact job, while the rate falls to $29 \%$ for first-generation African immigrants. These figures mean that even though employers hire African immigrants in occupations ' 561 ' or ' 631 ' that are characterized by a relatively high rate of contact, African immigrants are not exposed to customers (for instance, they are cleaners, kitchen helpers, or repairers in a repair shop with no home services).

The fact that our measurement of the contact probability is biased upwards for African workers does not affect the relevance of the test of customer discrimination. The phenomenon leads us to

underestimate the extent of discrimination, but should not increase the risk of 'false positives'situations where we conclude there is discrimination while there is not. 


\section{Lack of alternative EA-specific covariates}

Our second-step regressions omit typical characteristics of EAs like population density, urban worker proportion, and share of agricultural workers that have been proven to affect local economic outcomes. We omit these variables for four reasons. First, such variables certainly affect the overall probability of having a job as well as the overall probability of working in contact with the customers. First-step regressions include EA fixed-effects and so we control for these effects. Second, these variables are strongly correlated with the discriminatory forces we highlight throughout the paper. Namely, the proportion of contact jobs (the percentage of Non-Africans) increases (decreases) with population density and urban worker proportion, whereas it decreases (increases) with the share of agricultural workers. Including these variables would probably affect our results; but it would be very difficult to understand by which channels and what would be the correctly specified model. Third, we do not include these covariates because we do not have a proper theory for their inclusion. At the very least, the share of urban or agricultural workers can be seen as other proxies for the proportion of contact jobs. Similarly, and as far as discrimination is concerned, population density calls for underlying factors correlated with population density. Among them, of course, the proportion of contact jobs and the share of Non-African workers. Fourth, if the problem of these covariates is not an interpretable one but simply corresponds to an omitted variable problem, it is solved by the 2SLS estimation. It corrects not only for possible reverse causality but also for all omitted effects that would be correlated to both the share of Non-Africans and the variables explaining the local unemployment rate and the probability of being in contact with consumers.

\section{Conclusion}

The paper investigates the link between the over-exposure of African immigrants to unemployment in France and their under-representation in jobs in contact with customers. From a methodological perspective, we provide a test strategy to detect customer discrimination in survey data. We start with a two-sector matching model with two ethnic groups, ethnic sector-specific preferences, economy-wide employer discrimination, and sector-specific customer discrimination. We run the test on French individual data in a cross-section of Employment Areas. Our results indicate that there is customer discrimination in the French labor market for contact jobs.

Our work could be extended in several directions. On the theoretical side, wage setting and the labor demand could be made endogenous so as to predict the sectorial composition of jobs by EA. We could use such an enriched model to instrument (or to justify existing instruments for) the proportion of contact jobs in second-step regressions. In the same vein, we could try to model imperfect residential mobility between EAs. The demand for goods from the contact job sector could also be analyzed. Individual demand should depend on income. Customer discrimination would then respond to aggregate income for minority workers. On the empirical side, the test strategy could be applied to alternative datasets. Unlike France, there is residual wage disparity between racial groups in the US and so we need a version of the model where wages are endogenous. It would 
be interesting to assess whether the contact job proportion affects the residual black-white wage differential. 


\section{References}

Aeberhardt, R., Fougère, D., Pouget, J., and Rathelot, R. (2010). Wages and employment of french workers with african origin. Journal of Population Economics, 23(3):881-905.

Algan, Y., Dustmann, C., Glitz, A., and Manning, A. (2010). The economic situation of first and second-generation immigrants in france, germany and the united kingdom. Economic Journal, 120(542):F4-F30.

Becker, G. (1957). The Economics of discrimination, Chicago University Press, Chicago. Reprint 1971.

Black, D. (1995). Discrimination in an equilibrium search model. Journal of Labor Economics, 13(2):309-33.

Bowlus, A. and Eckstein, Z. (1998). Discrimination and skill differences in an equilibrium search model. Technical report.

Card, D. and Krueger, A. (1992). School quality and black-white relative earnings: A direct assessment. The Quarterly Journal of Economics, 107(1):151-200.

Cediey, E. and Foroni, F. (2006). Les discriminations à raison de 'l'origine' dans les embauches en france une enquête nationale par tests de discrimination selon la méthode du bit. Genève, Bureau international du Travail.

Charles, K. and Guryan, J. (2008). Prejudice and wages: An empirical assessment of becker's the economics of discrimination. Journal of Political Economy, 116(5):773-809.

Combes, P.-P., Decreuse, B., Schmutz, B., and Trannoy, A. (2011). The neighbor is king: customer discrimination in the housing market. mimeo GREQAM.

Conley, T. and Topa, G. (1999). Socio-economic distance and spatial patterns in unemployment. Technical report.

Cragg, J. and Donald, S. (1997). Inferring the rank of a matrix. Journal of Econometrics, 76:223-250.

Duguet, E., Leandri, N., L'Horty, Y., and Petit, P. (2010). Are young french jobseekers of ethnic immigrant origin discriminated against? a controlled experiment in the paris area. Annales d'Economie et de Statistique, 99-100:187-215.

Giuliano, L., Levine, D., and Leonard, J. (2009). Manager race and the race of new hires. Journal of Labor Economics, 27(4):589-631.

Giuliano, L., Levine, D., and Leonard, J. (2010). Customer discrimination. The Review of Economics and Statistics, 92(3):670-678. 
Gobillon, L., Magnac, T., and Selod, H. (2011). The effect of location on finding a job in the paris region. Journal of Applied Econometrics, 26(7):1079-1112.

Gobillon, L. and Selod, H. (2007). The effect of segregation and spatial mismatch on unemployment: Evidence from france. CEPR Discussion Papers 6198, C.E.P.R. Discussion Papers.

Heckman, J. J. (1979). Sample selection bias as a specification error. Econometrica, 47(1):153-61.

Holzer, H. J. and Ihlanfeldt, K. R. (1998). Customer discrimination and employment outcomes for minority workers. The Quarterly Journal of Economics, 113(3):835-867.

Ihlanfeldt, K. and Young, M. (1994). Intrametropolitan variation in wage rates: The case of atlanta fast-food restaurant workers. The Review of Economics and Statistics, 76(3):425-33.

Kahn, L. M. (1991). Discrimination in professional sports: A survey of the literature. Industrial and Labor Relations Review, 44(3):395-418.

Kahn, L. M. and Sherer, P. D. (1988). Racial differences in professional basketball players' compensation. Journal of Labor Economics, 6(1):40-61.

Kain, J. F. (1968). Housing segregation, negro employment, and metropolitan decentralization. The Quarterly Journal of Economics, 82(2):pp. 175-197.

Kenney, G. and Wissoker, D. (1994). An analysis of the correlates of discrimination facing young hispanic job-seekers. American Economic Review, 84(3):674-83.

Lang, K., Manove, M., and Dickens, W. (2005). Racial discrimination in labor markets with posted wage offers. American Economic Review, 95(4):1327-1340.

Nardinelli, C. and Simon, C. (1990). Customer racial discrimination in the market for memorabilia: The case of baseball. The Quarterly Journal of Economics, 105(3):575-95.

Patacchini, E. and Zenou, Y. (2008). Ethnic networks and employment outcomes. IZA Discussion Papers 3331, Institute for the Study of Labor (IZA).

Rosen, A. (2003). Search, bargaining, and employer discrimination. Journal of Labor Economics, $21(4): 807-830$.

Stock, J. H. and Yogo, M. (2002). Testing for weak instruments in linear iv regression. NBER Technical Working Papers 0284, National Bureau of Economic Research, Inc.

Sundstrom, W. A. (2007). The geography of wage discrimination in the pre civil rights south. The Journal of Economic History, 67(02):410-444. 


\section{Appendix}

\section{A Model in Directed Search}

$$
\begin{array}{r}
\frac{\partial \Delta u}{\partial n}=m\left[\left(1-\alpha_{e} n\right)\left[p \phi_{2}^{A}(n) \alpha_{c}-(1-p) \phi_{1}^{\prime}{ }^{A}(n)-p \phi_{2}^{\prime A}(n)\left(1-\alpha_{c} n\right)\right]\right. \\
\left.+\alpha_{e}\left[(1-p) \phi_{1}^{A}(n)+p \phi_{2}^{A}(n)\left(1-\alpha_{c} n\right)\right]\right]
\end{array}
$$

By definition, $\phi_{1}^{\prime}(n)>0$ and $\phi_{2}^{\prime}(n)<0$.

Claim 1. If $\partial \Delta u / \partial n>0$, then $a_{c}(n)>0$ or $a_{e}(n)>0$.

$$
\frac{\partial^{2} \Delta u}{\partial p \partial n}=m\left[\alpha_{e}\left[\phi_{2}^{A}(n)\left(1-\alpha_{c} n\right)-\phi_{1}^{A}(n)\right]+\left(1-\alpha_{e} n\right)\left[\phi_{1}^{\prime}{ }^{A}(n)-\phi_{2}^{\prime}{ }^{A}(n)\left(1-\alpha_{c} n\right)+\phi_{2}^{A}(n) \alpha_{c}\right]\right]
$$

If $a_{e}(n)=0$ and $a_{c}(n)=0$, this cross-effect should be zero since $\phi_{1}^{\prime A}(n)=0$ and $\phi_{2}^{\prime A}(n)=0$.

Claim 2. If $\partial^{2} \Delta u /(\partial p \partial n) \neq 0$, then $a_{c}(n)>0$ or $a_{e}(n)>0$.

Identifying customer discrimination. In the case of customer discrimination only - that is, $\alpha_{e}=0$ and $\alpha_{c}>0$-we have

$$
\frac{\partial^{2} \Delta u}{\partial p \partial n}=m\left[\phi_{1}^{\prime A}(n)-\phi_{2}^{\prime A}(n)\left(1-\alpha_{c} n\right)+\phi_{2}^{A}(n) \alpha_{c}\right]
$$

Since $\alpha_{c}>0, \phi_{1}^{\prime A}(n)>0$ and $\phi_{2}^{\prime A}(n)<0$, this derivative is positive.

When $\alpha_{c}=0$ and $\alpha_{e}>0$ :

$$
\frac{\partial^{2} \Delta u}{\partial p \partial n}=m\left[\left(1-\alpha_{e} n\right)\left[\phi_{1}^{\prime A}(n)-\phi_{2}^{\prime A}(n)\right]+\alpha_{e}\left[\phi_{2}^{A}(n)-\phi_{1}^{A}(n)\right]\right]
$$

Since $\alpha_{c}=0, \phi_{1}^{\prime A}(n)=0$ and $\phi_{2}^{\prime} A(n)=0$, this derivative is positive if and only if $\phi_{2}^{A}(n)-\phi_{1}^{A}(n)>0$. Equation (18) allows us to unambiguously identify customer from employer discrimination :

$$
\frac{\partial \Delta q}{\partial n}=\frac{p(1-p)\left(1-\alpha_{c} n\right)\left[\phi_{2}^{\prime A}(n) \phi_{1}^{A}(n)-\phi_{2}^{A}(n) \phi_{1}^{\prime A}(n)\right]-p(1-p) \alpha_{c} \phi_{1}^{A}(n) \phi_{2}^{A}(n)}{\left[(1-p) \phi_{1}^{A}(n)+p\left(1-\alpha_{c} n\right) \phi_{2}^{A}(n)\right]^{2}}
$$

This derivative is negative if and only if there is customer discrimination $\left(\phi_{1}^{\prime} A(n)>0\right.$ and $\left.\phi_{2}^{\prime}{ }^{A}(n)<0\right)$ which leads to our third claim. 
If $\alpha_{c}=0$, this derivative becomes :

$$
\frac{\partial \Delta q}{\partial n}=\frac{p(1-p)\left[\phi_{2}^{\prime} A(n) \phi_{1}^{A}(n)-\phi_{2}^{A}(n) \phi_{1}^{\prime A}(n)\right]}{\left[(1-p) \phi_{1}^{A}(n)+p \phi_{2}^{A}(n)\right]^{2}} .
$$

Since $\phi_{1}^{\prime A}(n)=0$ and $\phi_{2}^{\prime A}(n)=0$, then $\frac{\partial \Delta q}{\partial n}=0$.

Claim 3. $\partial \Delta q / \partial n<0$ if and only if $a_{c}(n)>0$ 


\section{B Distribution of wages in France}

A large majority of African immigrants are paid at the minimum wage which is set at 7.61 Euros (July 2004) :

Table 9: Distribution of wages (LFS 2005)

\begin{tabular}{lccc} 
& & & \\
\cline { 2 - 3 } & ]7E-8E[ & [8E-9E[ & Obs \\
\hline Total population & 19.65 & 16.82 & 10120 \\
Total population (full-time) & 20.71 & 18.01 & 8889 \\
Total population (full-time/private sector/low-skilled) & 26.63 & 20.43 & 5160 \\
Total population (full-time/private sector/low-skilled/1st generation) & 40.46 & 20.81 & 173 \\
Total population (full-time/private sector/low-skilled/2nd generation) & 37.31 & 22.39 & 67 \\
Total population (full-time/private sector/low-skilled/French natives) & 25.49 & 20.23 & 4009 \\
\hline
\end{tabular}

Sample: wage-earning workers (hourly-wage $>6.99$ ) ; Source : Labor Force Survey 2005 


\section{Dataset}

The French Census (1990) is available both at the individual and city level. The 1990 Census full sample includes a quarter of the total French population $(1,417,6821$ observations). Table 10 describes the ethnic groups that we construct in this paper. Information on individuals' citizenship (actual and former) allows us to identify minority groups. Unlike the Labor Force survey, the Census does not provide this type of information for the parents. Consequently, we only consider first-generation African immigrants: persons who were born in Africa with an African country citizenship at birth. Unfortunately, second-generation immigrants belong to the group of French natives. Table 11 describes the construction of the male low-skilled worker sample used in this paper.

Table 10: Ethnic groups in the 1990 French Census (Full sample)

\begin{tabular}{lcc}
\hline Ethnic groups & Observations & Percentage \\
\hline French natives & $12,726,437$ & $91.64 \%$ \\
Africans & 412,659 & $2.97 \%$ \\
Europeans & 632,531 & $4.55 \%$ \\
Others & 115,392 & $0.84 \%$ \\
\hline
\end{tabular}

Notes: (i) French natives are born French at birth; (ii) Africans that we consider are born in Africa and can either have foreign citizenship or have French citizenship (by acquisition); (iii) Europeans considered are born in Europe and can either have foreign citizenship or have French citizenship (by acquisition); (iv) Source: 1990 French Census. 
Table 11: Restricted sample of the 1990 French Census

\begin{tabular}{lc}
\hline Full Sample & $\mathbf{1 4 , 1 7 6 , 8 2 1}$ \\
Restrict to men who live in France between the ages of 25 and 60 & $3,318,643$ \\
Exclusion criteria & \\
Neither African nor French & 263,493 \\
Non working (Retired, military, enrolled in school) & 164,700 \\
Diploma > High-School level & 518,366 \\
In Public Sector & 736,779 \\
Self-employed & 446,183 \\
Not in France in 1982 & 68,419 \\
Not in relevant occupations & 699,175 \\
Final sample & $\mathbf{1 , 3 7 6 , 1 7 6}$ \\
French natives & $1,277,420(92.82 \%)$ \\
Africans & $98,756(7.18 \%)$ \\
\hline Low-skilled workers in the private sector & $1,087,179(79.74 \%)$ \\
Unemployed individuals & $278,813(20.26 \%)$ \\
\hline
\end{tabular}

Notes: (i) The exclusion criteria are not mutually exclusive, so many observations show up in multiple rows; (ii) Irrelevant occupations include public occupations or high-skilled occupations; (iii) French natives are born French; (iv) Africans are born in Africa and can either have foreign or French citizenship (by acquisition); (v) Source : 1990 French Census. 


\section{Proportion of contact jobs by occupation}

Table 12: Proportion of contact jobs by occupation

\begin{tabular}{|c|c|c|c|c|c|}
\hline Occupation & \%Contact & t \# & Occupation & \%Contact & t \# \\
\hline \multicolumn{6}{|l|}{ Liberal Professions (3) } \\
\hline Journalists/ Writers & 0.571 & 7 & Managers (Hotel \& food service) & 0.8 & 10 \\
\hline Managers (publishing, entertainment) & 0.524 & 21 & Technical Directors/managers & 0.5 & 6 \\
\hline Craft artists, Musicians, Dancers & 0.821 & 28 & Engineering Managers (R \& D) & 0.560 & 107 \\
\hline Managers & 0.638 & 47 & Engineering Managers (production) & 0.486 & 190 \\
\hline Administrative services Managers & 0.483 & 44 & Engineering Managers (maintenance) & 0.522 & 23 \\
\hline Public Relations \& Sales Managers & 0.776 & 134 & Engineering Technicians (electrical) & 0.93 & 29 \\
\hline Managers (Bank \& Insurance) & 0.660 & 103 & Engineering Technicians (logistics) & 0.5 & 18 \\
\hline \multicolumn{6}{|l|}{ Intermediate occupations (4) } \\
\hline Nurses & 0.935 & 31 & Medical technicians and specialists & 0.809 & 84 \\
\hline Medical \& Public health social workers & 0.84 & 100 & Exec Secretaries \& Admin Assistants & 0.526 & 302 \\
\hline Sales Agents/Representatives & 0.869 & 659 & Technical Assistants (communication) & 0.641 & 39 \\
\hline Transportation Admin Managers & 0.638 & 58 & Technical Assistants (insurance) & 0.712 & 146 \\
\hline Technical Assistants (Hotel) & 0.638 & 58 & & & \\
\hline \multicolumn{6}{|l|}{$\underline{\text { Technicians }}$} \\
\hline Agricultural & 0.667 & 18 & Electricians & 0.426 & 101 \\
\hline Mechanical & 0.189 & 164 & Construction and Building & 0.647 & 51 \\
\hline Metal & 0.189 & 164 & Printing & 0.381 & 21 \\
\hline Production & 0.468 & 231 & Miscellaneous & 0.625 & 72 \\
\hline \multicolumn{6}{|l|}{ First-Line Supervisors } \\
\hline Agricultural & 0.412 & 51 & Electricians & 0.400 & 10 \\
\hline Mechanical & 0.439 & 82 & Construction and Building & 0.641 & 128 \\
\hline Chemistry, Food Industry & 0.284 & 95 & Metal & 0.284 & 95 \\
\hline Distribution & 0.341 & 44 & Maintenance & 0.438 & 105 \\
\hline Miscellaneous & 0.571 & & & & \\
\hline \multicolumn{6}{|l|}{ Clerks / Office Workers (5) } \\
\hline Secretaries & 0.705 & 695 & Accountants, financial officer & 0.398 & 855 \\
\hline Clerks (Bank, Insurance) & 0.543 & 151 & Transportation clerks & 0.832 & 82 \\
\hline Shop clerks & 0.949 & 1146 & Gas pump attendants & 0.958 & 24 \\
\hline Waiters, Cooks, Desk Clerks & 0.807 & 388 & Hairdressers, Manicurists & 0.986 & 148 \\
\hline Child/Home Care Workers, Concierges & 0.748 & 1325 & & & \\
\hline \multicolumn{6}{|l|}{ Operators/workers (6) } \\
\hline \multicolumn{6}{|l|}{ Skilled (industrial) } \\
\hline Maintenance & 0.247 & & Electricians & 0.112 & 98 \\
\hline Production : Metal & 0.124 & 290 & Production : Mechanical & 0.111 & 244 \\
\hline
\end{tabular}

Continued on Next Page 
Table 12 - Continued

\begin{tabular}{|c|c|c|c|c|c|}
\hline Occupation & \%Contact & $\#$ & Occupation & \%Contact & t \# \\
\hline Production : Construction \& Building & 0.445 & 155 & Production : Processing & 0.098 & 284 \\
\hline Production : Processing & 0.033 & 91 & Production : Textile & 0.171 & 251 \\
\hline Production : Printing & 0.171 & 251 & Production : Woodworking & 0.239 & 221 \\
\hline \multicolumn{6}{|l|}{ Skilled (Craft) } \\
\hline Gardeners & 0.644 & 59 & Electricians & 0.724 & 98 \\
\hline Mechanical/Metal & 0.674 & 224 & Woodworking & 0.553 & 85 \\
\hline Construction \& Building & 0.600 & 610 & Food Industry & 0.520 & 275 \\
\hline Textile & 0.378 & 45 & Artists & 0.456 & 46 \\
\hline$\underline{\text { Drivers (Bus, Truck, Taxi) }}$ & 0.770 & 681 & & & \\
\hline \multicolumn{6}{|l|}{ Skilled (Misc) } \\
\hline Handling & 0.316 & 415 & Transportation & 0.417 & 30 \\
\hline Ship \& Boat Captains & 0.400 & 5 & & & \\
\hline \multicolumn{6}{|l|}{ Unskilled (industrial) } \\
\hline Electricians & 0.082 & 61 & Mechanical/Metal & 0.061 & 261 \\
\hline Construction and Building & 0.216 & 51 & Processing & 0.057 & 322 \\
\hline Woodworking/Recycling & 0.078 & 519 & Textile & 0.0826 & 173 \\
\hline \multicolumn{6}{|l|}{ Unskilled (Craft) } \\
\hline Mechanical/metal & 0.606 & 66 & Construction and Building & 0.405 & 215 \\
\hline Food Industry & 0.357 & 14 & Janitors/Misc & 0.378 & 473 \\
\hline \multicolumn{6}{|l|}{ Agricultural/Fish Workers } \\
\hline Farm workers & 0.198 & 282 & Fishers & 0.133 & 15 \\
\hline
\end{tabular}

Notes: (i) Sample: low-skilled (who have a high-school diploma or less) wage-earning men in the private sector; (ii) One-digit occupations are in bold; (iii) Source: 2003 FQP survey. 


\section{E First-Step Results}

Table 13: Probability of unemployment: first-step results

\begin{tabular}{|c|c|c|c|c|}
\hline & (1) & $(2)$ & $(3)$ & $(4)$ \\
\hline African & $\begin{array}{c}0.83^{a} \\
(0.013)\end{array}$ & $\begin{array}{c}0.71^{a} \\
(0.013)\end{array}$ & $\begin{array}{c}0.66^{a} \\
(0.054)\end{array}$ & $\begin{array}{c}0.51^{a} \\
(0.096)\end{array}$ \\
\hline Age & $\begin{array}{c}-0.020^{a} \\
(0.00015)\end{array}$ & $\begin{array}{c}-0.018^{a} \\
(0.00014)\end{array}$ & $\begin{array}{c}-0.019^{a} \\
(0.00015)\end{array}$ & $\begin{array}{c}-0.018^{a} \\
(0.00014)\end{array}$ \\
\hline Age Squared & $\begin{array}{c}0.00032^{a} \\
(0.000002)\end{array}$ & $\begin{array}{c}0.00029^{a} \\
(0.000002)\end{array}$ & $\begin{array}{c}0.00032^{a} \\
(0.0000018)\end{array}$ & $\begin{array}{c}0.0029^{a} \\
(0.0000017)\end{array}$ \\
\hline Junior HS Diploma & $\begin{array}{c}-0.058^{a} \\
(0.00068)\end{array}$ & $\begin{array}{c}-0.041^{a} \\
(0.00054)\end{array}$ & $\begin{array}{c}-0.057^{a} \\
(0.00067)\end{array}$ & $\begin{array}{c}-0.041^{a} \\
(0.000536)\end{array}$ \\
\hline Vocational Diploma & $\begin{array}{c}-0.093^{a} \\
(0.00037)\end{array}$ & $\begin{array}{c}-0.082^{a} \\
(0.00032)\end{array}$ & $\begin{array}{c}-0.089^{a} \\
(0.00036)\end{array}$ & $\begin{array}{c}-0.078^{a} \\
(0.00032)\end{array}$ \\
\hline HS Diploma & $\begin{array}{c}-0.109^{a} \\
(0.00053)\end{array}$ & $\begin{array}{c}-0.08^{a} \\
(0.00037)\end{array}$ & $\begin{array}{c}-0.102^{a} \\
(0.00053)\end{array}$ & $\begin{array}{c}-0.080^{a} \\
(0.00037)\end{array}$ \\
\hline Married & $\begin{array}{c}-0.18^{a} \\
(0.00036)\end{array}$ & $\begin{array}{c}-0.19^{a} \\
(0.00042)\end{array}$ & $\begin{array}{l}-0.18^{a} \\
(0.0037)\end{array}$ & $\begin{array}{c}-0.19^{a} \\
(0.00042)\end{array}$ \\
\hline No Kid & $\begin{array}{c}-0.021^{a} \\
(0.00038)\end{array}$ & $\begin{array}{c}-0.015^{a} \\
(0.00036)\end{array}$ & $\begin{array}{c}-0.018^{a} \\
(0.00038)\end{array}$ & $\begin{array}{c}-0.013^{a} \\
(0.00036)\end{array}$ \\
\hline African $\times$ Age & $\begin{array}{c}-0.031^{a} \\
(0.00064)\end{array}$ & $\begin{array}{c}-0.018^{a} \\
(0.00055)\end{array}$ & $\begin{array}{c}-0.029^{a} \\
(0.00064)\end{array}$ & $\begin{array}{c}-0.016^{a} \\
(0.00054)\end{array}$ \\
\hline African $\times$ Age Squared & $\begin{array}{c}0.00029^{a} \\
(0.0000075)\end{array}$ & $\begin{array}{c}0.00014^{a} \\
(0.0000056)\end{array}$ & $\begin{array}{c}0.00027^{a} \\
(0.0000074)\end{array}$ & $\begin{array}{c}0.00012^{a} \\
(0.0000063)\end{array}$ \\
\hline African $\times$ Junior HS Diploma & $\begin{array}{c}0.033^{a} \\
(0.0036)\end{array}$ & $\begin{array}{c}0.036^{a} \\
(0.0026)\end{array}$ & $\begin{array}{c}0.037^{a} \\
(0.0036)\end{array}$ & $\begin{array}{c}0.036^{a} \\
(0.0037)\end{array}$ \\
\hline African $\times$ Vocational Diploma & $\begin{array}{c}0.032^{a} \\
(0.0019)\end{array}$ & $\begin{array}{c}0.053^{a} \\
(0.0021)\end{array}$ & $\begin{array}{c}0.021^{a} \\
(0.0019)\end{array}$ & $\begin{array}{c}0.040^{a} \\
(0.0021)\end{array}$ \\
\hline African $\times$ HS Diploma & $\begin{array}{c}0.057^{a} \\
(0.0032)\end{array}$ & $\begin{array}{c}0.087^{a} \\
(0.0038)\end{array}$ & $\begin{array}{c}0.059^{a} \\
(0.0032)\end{array}$ & $\begin{array}{c}0.083^{a} \\
(0.0038)\end{array}$ \\
\hline African $\times$ Married & $\begin{array}{c}0.025^{a} \\
(0.0072)\end{array}$ & $\begin{array}{c}0.076^{a} \\
(0.0017)\end{array}$ & $\begin{array}{c}0.029^{a} \\
(0.0012)\end{array}$ & $\begin{array}{c}0.081^{a} \\
(0.0018)\end{array}$ \\
\hline African $\times$ No Kid & $\begin{array}{l}-0.018^{a} \\
(0.0014)\end{array}$ & $\begin{array}{c}-0.012^{a} \\
(0.00036)\end{array}$ & $\begin{array}{l}-0.019^{a} \\
(0.0014)\end{array}$ & $\begin{array}{l}-0.013^{a} \\
(0.0012)\end{array}$ \\
\hline $\begin{array}{l}\text { EA fixed effects } \\
\text { EA fixed effects } \times \text { 'African' }\end{array}$ & & & $\begin{array}{l}\text { yes } \\
\text { yes }\end{array}$ & $\begin{array}{l}\text { yes } \\
\text { yes }\end{array}$ \\
\hline Observations & $1,411,300$ & $1,411,300$ & $1,411,300$ & $1,411,300$ \\
\hline $\mathrm{R}^{2}$ & 0.10 & 0.11 & 0.12 & 0.13 \\
\hline
\end{tabular}

Notes: (i) Standard errors in brackets; (ii) Significance levels : a: 1\%, b: 5\%, c: 10\% ; (iii) Sample: low-skilled men between 25 and 60; (iv) Columns (1) and (3) are a linear probability model and columns (2) and (4) a probit model. 
Table 14: Probability of being in contact among employees: first-step results

\begin{tabular}{|c|c|c|c|c|}
\hline & $(1)$ & $(2)$ & $(3)$ & $(4)$ \\
\hline African & $\begin{array}{c}0.29^{a} \\
(0.012)\end{array}$ & $\begin{array}{c}0.012 \\
(0.011)\end{array}$ & $\begin{array}{l}-0.010 \\
(0.18)\end{array}$ & $\begin{array}{c}-0.28^{b} \\
(0.12)\end{array}$ \\
\hline Age & $\begin{array}{l}0.00064^{a} \\
(0.00012)\end{array}$ & $\begin{array}{l}-0.0037^{a} \\
(0.00011)\end{array}$ & $\begin{array}{c}0.0011^{a} \\
(0.00012)\end{array}$ & $\begin{array}{l}-0.0034^{a} \\
(0.00011)\end{array}$ \\
\hline Age Squared & $\begin{array}{c}0.000014^{a} \\
(0.0000016)\end{array}$ & $\begin{array}{c}0.00004^{a} \\
(0.0000014)\end{array}$ & $\begin{array}{c}0.000007^{a} \\
(0.0000015)\end{array}$ & $\begin{array}{c}0.000036^{a} \\
(0.00000112)\end{array}$ \\
\hline Junior HS Diploma & $\begin{array}{c}0.13^{a} \\
(0.0025)\end{array}$ & $\begin{array}{c}0.020^{a} \\
(0.00049)\end{array}$ & $\begin{array}{c}0.11^{a} \\
(0.00052)\end{array}$ & $\begin{array}{c}0.014^{a} \\
(0.00048)\end{array}$ \\
\hline Vocational Diploma & $\begin{array}{c}0.027^{a} \\
(0.00032)\end{array}$ & $\begin{array}{c}-0.00071^{b} \\
(0.00029)\end{array}$ & $\begin{array}{c}0.022^{a} \\
(0.00032)\end{array}$ & $\begin{array}{l}-0.0029^{a} \\
(0.00029)\end{array}$ \\
\hline HS Diploma & $\begin{array}{c}0.14^{a} \\
(0.00043)\end{array}$ & $\begin{array}{c}-0.015^{a} \\
(0.00043)\end{array}$ & $\begin{array}{c}0.12^{a} \\
(0.00043)\end{array}$ & $\begin{array}{c}-0.019^{a} \\
(0.00042)\end{array}$ \\
\hline African $\times$ Age & $\begin{array}{c}-0.014^{a} \\
(0.00056)\end{array}$ & $\begin{array}{c}-0.0027^{a} \\
(0.00050)\end{array}$ & $\begin{array}{c}-0.013^{a} \\
(0.00055)\end{array}$ & $\begin{array}{c}-0.0016^{a} \\
(0.00049)\end{array}$ \\
\hline African $\times$ Age Squared & $\begin{array}{c}0.00013^{a} \\
(0.0000065)\end{array}$ & $\begin{array}{c}0.000028^{a} \\
(0.0000058)\end{array}$ & $\begin{array}{c}0.00011^{a} \\
(0.0000064)\end{array}$ & $\begin{array}{c}0.000013^{a} \\
(0.0000058)\end{array}$ \\
\hline African $\times$ Junior HS Diploma & $\begin{array}{c}0.0037 \\
(0.0030)\end{array}$ & $\begin{array}{c}0.023^{a} \\
(0.0028)\end{array}$ & $\begin{array}{c}0.0054^{c} \\
(0.0030)\end{array}$ & $\begin{array}{c}0.026^{a} \\
(0.0027)\end{array}$ \\
\hline African $\times$ Vocational Diploma & $\begin{array}{c}0.018^{a} \\
(0.0016)\end{array}$ & $\begin{array}{c}0.028^{a} \\
(0.0015)\end{array}$ & $\begin{array}{c}0.026^{a} \\
(0.0016)\end{array}$ & $\begin{array}{c}0.032^{a} \\
(0.0015)\end{array}$ \\
\hline African $\times$ HS Diploma & $\begin{array}{c}0.029^{a} \\
(0.0027)\end{array}$ & $\begin{array}{c}0.030^{a} \\
(0.0026)\end{array}$ & $\begin{array}{c}0.028^{a} \\
(0.0027)\end{array}$ & $\begin{array}{c}0.032^{a} \\
(0.0026)\end{array}$ \\
\hline Occupation group 3 & & $\begin{array}{c}0.27^{a} \\
(0.00045)\end{array}$ & & $\begin{array}{c}0.26^{a} \\
(0.00045)\end{array}$ \\
\hline Occupation group 4 & & $\begin{array}{c}0.22^{a} \\
(0.00029)\end{array}$ & & $\begin{array}{c}0.22^{a} \\
(0.00030)\end{array}$ \\
\hline Occupation group 5 & & $\begin{array}{c}0.33^{a} \\
(0.00045)\end{array}$ & & $\begin{array}{c}0.32^{a} \\
(0.00045)\end{array}$ \\
\hline African $\times$ Occupation group 3 & & $\begin{array}{c}0.037^{a} \\
(0.0038)\end{array}$ & & $\begin{array}{c}0.024^{a} \\
(0.0037)\end{array}$ \\
\hline African $\times$ Occupation group 4 & & $\begin{array}{c}0.049^{a} \\
(0.0021)\end{array}$ & & $\begin{array}{l}0.0401^{a} \\
(0.0021)\end{array}$ \\
\hline African $\times$ Occupation group 5 & & $\begin{array}{c}0.12^{a} \\
(0.0019)\end{array}$ & & $\begin{array}{c}0.11^{a} \\
(0.00039)\end{array}$ \\
\hline $\begin{array}{l}\text { EA fixed effects } \\
\text { EA fixed effects } \times \text { 'African' }\end{array}$ & & & $\begin{array}{l}\text { yes } \\
\text { yes }\end{array}$ & $\begin{array}{l}\text { yes } \\
\text { yes }\end{array}$ \\
\hline Observations & $1,153,600$ & $1,153,600$ & $1,153,600$ & $1,153,600$ \\
\hline $\mathrm{R}^{2}$ & 0.04 & 0.22 & 0.08 & 0.24 \\
\hline
\end{tabular}

Notes: (i) Standard errors in brackets; (ii) Significance levels: a: 1\%, b: 5\%, c: 10\% ; (iii) Sample: low-skilled wage-earning men between 25 and 60; (iv) Specifications are corrected for sample selection bias. 


\section{F Estimated EA fixed-effects and labor market outcomes}

Figure 3: EA fixed-effects of the unemployment regression

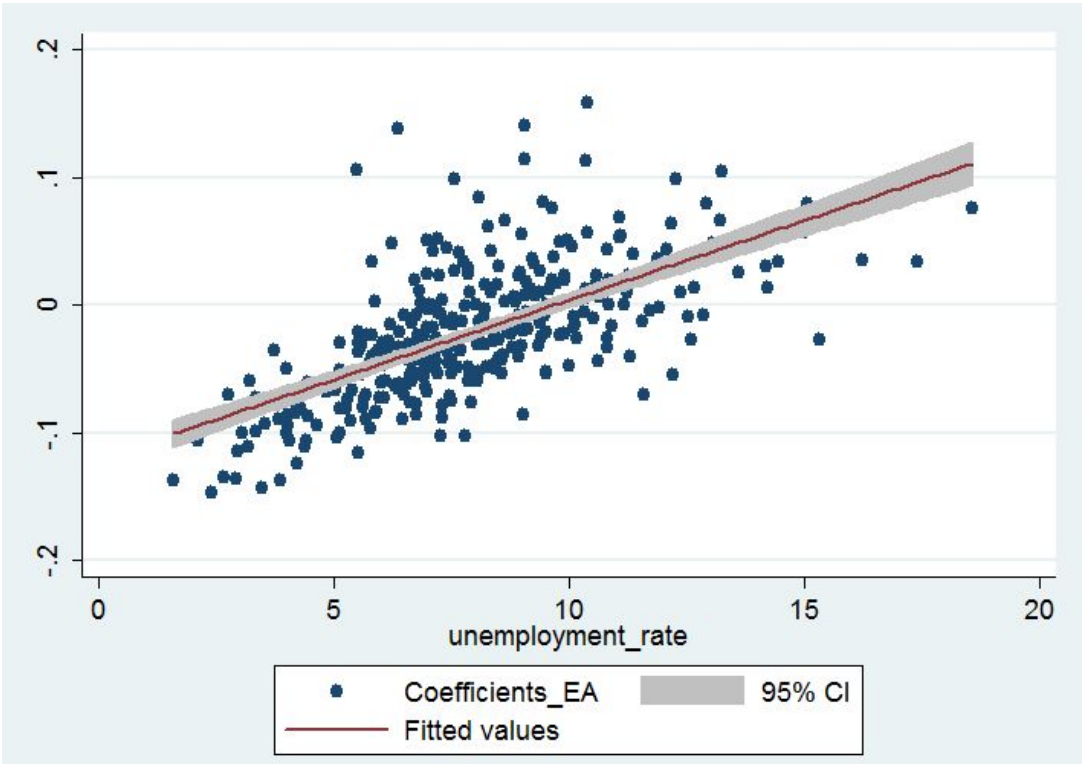

Notes: (i) The figure reports the EA fixed effects of the first-step unemployment regression (3), (ii) Each point represents the estimated coefficient of each EA by unemployment rate, the figure gives equal weight to each EA; (iii) The solid line shows the fitted values, and the gray area shows the confidence interval at 95\% ; (iv) Source: 1990 French Census, 2003 FQP survey, and authors' computations. 
Figure 4: EA fixed-effects of contact rate regression

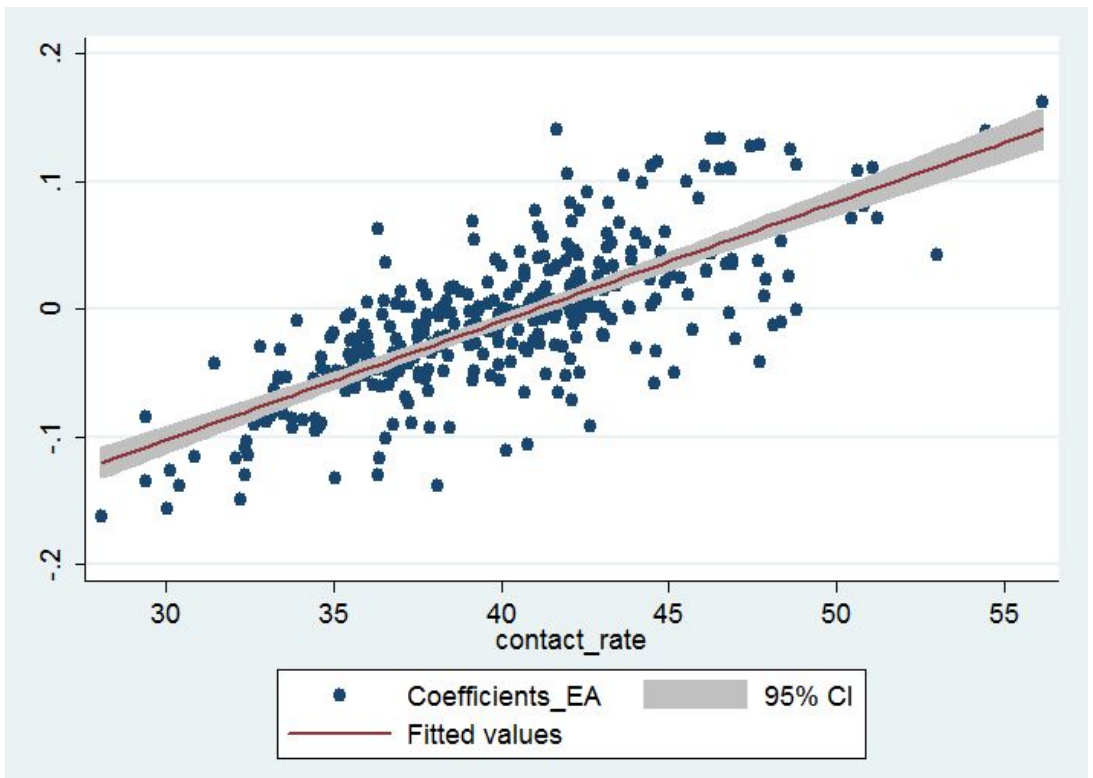

Notes: (i) The figure reports the EA fixed effects of the first-step contact rate regression (4), (ii) Each point represents the estimated coefficient of each EA by contact rate, the figure gives equal weight to each EA; (iii) The solid line shows the fitted values, and the grey area shows the confidence interval at 95\% ; (iv) Source: 1990 French Census, 2003 FQP survey, and authors' computations. 


\section{G Probit Results (Second-Step)}

Table 15: Second-step regression results on the probability of unemployment

\begin{tabular}{lcc}
\hline Specifications & $(1)$ & $(2)$ \\
\hline \%Contact & $0.0020^{b}$ & $0.0025^{b}$ \\
& $(0.0010)$ & $(0.0012)$ \\
\%Non-Africans & $0.020^{a}$ & $0.014^{a}$ \\
& $(0.0049)$ & $(0.0065)$ \\
\%Contact $\%$ Non-Africans & $0.0016^{b}$ \\
Constant & $(0.00072)$ \\
& $-1.84^{a}$ & $6.46^{c}$ \\
Observations & $(0.49)$ & $(3.59)$ \\
$\mathrm{R}^{2}$ & 290 & 290 \\
\hline
\end{tabular}

Notes: (i) Weighted least squares regressions using the inverse of estimated variance of coefficients from first-step regression reported in Table 3 as weights; (ii) Standard errors in brackets. Significance levels : a: 1\%, b: $5 \%$, c: $10 \%$; (iii) Columns are estimated using a first-step Probit model in Table 4. 


\section{H Single-Step unemployment estimations (Sub-Saharan vs North Africans)}

Table 16: Probability of being unemployed

\begin{tabular}{lcc}
\hline Specifications & $(1)$ & $(2)$ \\
\hline Sub-Saharan African & $0.161^{a}$ & $0.159^{a}$ \\
& $(0.0036)$ & $(0.0043)$ \\
Sub-Saharan AfricanX\%Contact & $0.00269^{a}$ & $0.00280^{a}$ \\
& $(0.00038)$ & $(0.00059)$ \\
Sub-Saharan AfricanX\%Non-(Sub-Saharan)Africans & $0.0747^{a}$ & $0.0733^{a}$ \\
& $(0.0039)$ & $(0.0064)$ \\
Sub-Saharan AfricanX\%ContactX\%Non-(Sub-Saharan)Africans & & 0.000584 \\
& & $(0.00093)$ \\
North-African & $0.104^{a}$ & $0.103^{a}$ \\
North-AfricanX\%Contact & $(0.0012)$ & $(0.0014)$ \\
& $0.000863^{a}$ & $0.00149^{a}$ \\
North-AfricanX\%Non-(North)Africans & $(0.00012)$ & $(0.00019)$ \\
& $0.0130^{a}$ & $0.0119^{a}$ \\
North-AfricanX\%ContactX\%Non-(North)Africans & $(0.00046)$ & $(0.00067)$ \\
& & $0.000688^{a}$ \\
Controls & & $(0.000090)$ \\
& & $\mathrm{X}$ \\
Observations & & $1,411,300$ \\
Pseudo-R ${ }^{2}$ & $1,411,300$ & 0.114 \\
\hline
\end{tabular}

Notes: (i) Marginal effects are reported ; (ii) Significance levels : a: 1\%, b: 5\%, c: 10\% ; (iii) Sample: low-skilled wage-earning men between 25 and 60; (iv) Fixed-effects EA are included; (v) Individual controls are age, a quadratic in age, education dummies, marital status and the presence of kids ; (vi) Estimations using a LPM model ; (vii) Source: French Census 1990. 


\section{Single-Step estimations}

Table 17: Probability of being unemployed

\begin{tabular}{lcccc}
\hline Specifications & $(1)$ & $(2)$ & $(3)$ & $(4)$ \\
\hline African & $0.104^{a}$ & $0.110^{a}$ & $0.101^{a}$ & $0.0989^{a}$ \\
& $(0.0065)$ & $(0.0069)$ & $(0.0079)$ & $(0.0082)$ \\
AfricanX\%Contact & $0.0011^{a}$ & $0.000967^{a}$ & $0.00111^{a}$ & $0.00159^{a}$ \\
& $(0.00034)$ & $(0.000316)$ & $(0.000112)$ & $(0.00018)$ \\
AfricanX\%Non-Africans & $0.0065^{a}$ & $0.00959^{a}$ & $0.0113^{a}$ & $0.0104^{a}$ \\
& $(0.00188)$ & $(0.000476)$ & $(0.000352)$ & $(0.000527)$ \\
AfricanX\%ContactX\%Non-Africans & & $0.000527^{a}$ & & $0.000482^{a}$ \\
Controls & $\mathrm{X}$ & $(0.0000934)$ & $\mathrm{X}$ & $(0.0000718)$ \\
Observations & $1,411,300$ & $1,411,300$ & $1,411,300$ & $1,411,300$ \\
Pseudo-R & 0.12 & 0.12 & 0.11 & 0.11 \\
\hline
\end{tabular}

Notes: (i) Marginal effects are reported ; (ii) Significance levels : ***: 1\%, **: 5\%, *: 10\%; (iii) Sample: low-skilled wage-earning men between 25 and 60; (iv) Fixed-effects ZE are included ; (v) Individual controls are age, a quadratic in age, education dummies, marital status and the presence of kids ; (vi) Columns (1) and (2) are estimated using a Probit model, and columns (3) and (4) are estimated using a LPM model ; (vii) Source: French Census 1990.

Table 18: Probability of being in contact with the public

\begin{tabular}{lcccc}
\hline Specifications & $(1)$ & $(2)$ & $(3)$ & $(4)$ \\
\hline African & $-0.0491^{a}$ & $-0.104^{a}$ & $-0.0514^{a}$ & $-0.110^{a}$ \\
& $(0.00049)$ & $(0.00053)$ & $(0.00048)$ & $(0.00052)$ \\
African X \%Non-Africans & $-0.0034^{a}$ & $-0.0029^{a}$ & $-0.0036^{a}$ & $-0.0033^{a}$ \\
& $(0.00024)$ & $(0.00027)$ & $(0.00024)$ & $(0.00027)$ \\
Controls: Age \& education & $\mathrm{X}$ & $\mathrm{X}$ & $\mathrm{X}$ & $\mathrm{X}$ \\
Controls: Occupations & $\mathrm{X}$ & & $\mathrm{X}$ & \\
\hline Observations & $1,153,600$ & $1,153,600$ & $1,153,600$ & $1,153,600$ \\
Pseudo-R & 0.24 & 0.08 & 0.24 & 0.08 \\
\hline
\end{tabular}

Notes: (i) Marginal effects are reported; (ii) Significance levels : a: 1\%, b: 5\%, c: 10\% ; (iii) Sample: low-skilled wage-earning men between 25 and 60; (iv) Fixed-effects ZE are included; (v) Individual controls are age, a quadratic in age, education dummies and occupation dummies in columns (1), (2) and (3) ; (vi) Columns (1) and (2) are corrected for sample selection bias (Two-step Heckman Model), and columns (3) and (4) are not ; (vii) Source: French Census 1990. 